\title{
A Contribution by Ice Nuclei to Global Warming
}

Xiping Zeng ${ }^{1,2}$, Wei-Kuo Tao ${ }^{2}$, Minghua Zhang ${ }^{3}$, Arthur Y. Hou ${ }^{2}$, Shaocheng Xie ${ }^{4}$, Stephen Lang ${ }^{2,5}$, Xiaowen $\mathrm{Li}^{1,2}$, David O'C Starr ${ }^{2}$, and Xiaofan $\mathrm{Li}^{6}$

${ }^{1}$ Goddard Earth Sciences and Technology Center, University of Maryland at Baltimore County, Baltimore, Maryland, USA

${ }^{2}$ Laboratory for Atmospheres, NASA Goddard Space Flight Center, Greenbelt, Maryland, USA

${ }^{3}$ School of Marine and Atmospheric Sciences, Stony Brook University, New York, USA

${ }^{4}$ Atmospheric Sciences Division, Lawrence Livermore National Laboratory, Livermore, California, USA

${ }^{5}$ Science Systems and Applications Inc., Lanham, Maryland, USA

${ }^{6}$ National Environmental Satellite, Data, and Information Service, NOAA, Camp Spring, Maryland, USA

$\left(3^{\text {rd }}\right.$ revision $)$

Submitted to the Quarterly Journal of the Royal Meteorological Society

April 17, 2009

Corresponding author address: Dr. Xiping Zeng, C423, Bldg 33, Mail Code 613.1, NASA Goddard Space Flight Center, Greenbelt, MD 20771. Email: zeng@agnes.gsfc.nasa.gov. 


\begin{abstract}
Ice nuclei (IN) significantly affect clouds via supercooled droplets, that in turn modulate atmospheric radiation and thus climate change. Since the IN effect is relatively strong in stratiform clouds but weak in convective ones, the overall effect depends on the ratio of stratiform to convective cloud amount. In this paper, 10 years of TRMM (Tropical Rainfall Measuring Mission) satellite data are analyzed to confirm that stratiform precipitation fraction increases with increasing latitude, which implies that the IN effect is stronger at higher latitudes.

To quantitatively evaluate the IN effect versus latitude, large-scale forcing data from ten field campaigns are used to drive a CRM (cloud-resolving model) to generate longterm cloud simulations. As revealed in the simulations, the increase in the net downward radiative flux at the TOA (top of the atmosphere) from doubling the current IN concentrations is larger at higher latitude, which is attributed to the meridional tendency in the stratiform precipitation fraction.

Surface warming from doubling the IN concentrations, based on the radiative balance of the globe, is compared with that from anthropogenic $\mathrm{CO}_{2}$. It is found that the former effect is stronger than the latter in middle and high latitudes but not in the Tropics.

With regard to the impact of IN on global warming, there are two factors to consider: the radiative effect from increasing the IN concentration and the increase in IN concentration itself. The former relies on cloud ensembles and thus varies mainly with latitude. In contrast, the latter relies on IN sources (e.g., the land surface distribution) and thus varies not only with latitude but also longitude. Global desertification and industrialization provide clues on the geographic variation of the increase in IN
\end{abstract}


concentration since pre-industrial times. Thus, their effect on global warming can be inferred and then be compared with observations. A general match in geographic and seasonal variations between the inferred and observed warming suggests that IN may have contributed positively to global warming over the past decades, especially in middle and high latitudes. 


\section{Introduction}

The global trend in air surface temperature, such as that over the period 1979 to 2005 , is highly variable from one region to another (IPCC 2007, p. 253). Since carbon dioxide $\left(\mathrm{CO}_{2}\right)$ and other greenhouse gases as well as their effect on global warming are horizontally uniform in distribution, it is still unclear how they could cause the observed geographical variation in warming via a feedback mechanism (IPCC 2007; see Section 5 for more discussion). Thus, other contributions to global warming may exist beyond greenhouse gases (e.g., Lindzen 1990; Ramanathan et al. 2007; Prenni et al. 2007).

Aerosol particles, owing to their direct (Ramanathan et al. 2007; Wild et al. 2007) and indirect (NRC, National Research Council 2005; Lohmann and Feichter 2005; Zhang et al. 2007) effects on the radiation budget of the Earth, may be responsible for the geographical variation in global warming (Baker 1997; Prenni et al. 2007). Recent cloudresolving model (CRM) simulations have revealed that ice nuclei (IN), a class of aerosol particles, can significantly affect cloud ensembles (Phillips et al. 2005; Ekman et al. 2007; Phillips et al. 2007; Zeng et al. 2008b) and in turn radiation (Zeng et al. 2009, see Section 2 for more discussion). An interesting question is whether IN have contributed to the geographical variation in global warming.

The present paper proposes a connection between increasing IN concentration and global warming. It consists of five sections. In Section 2, TRMM satellite data are analyzed to show a meridional variation in stratiform precipitation fraction and then a meridional tendency in the IN effect is proposed. In Section 3, CRM simulations at various latitudes are used to confirm and quantify the tendency. In Section 4, the geographic variation of $\mathrm{IN}$-induced warming is inferred and the inferred variation 
compared with observations. Section 5 concludes.

\section{A meridional tendency in the IN effect}

This section as well as the next one addresses meridional and seasonal variations in radiation when the current IN concentration is doubled. First, it traces the origin of the IN effect downscale to supercooled droplets and then explains why the IN effect relies on the ratio between stratiform and convective precipitation rates. Second, it analyzes 10 years of TRMM data to quantify the ratio versus latitude, ending with the prediction that there exists a meridional tendency in the effects of IN.

\section{a. Origin of the IN effect}

The IN effect originates with the coexistence of ice crystals and supercooled droplets in mixed-phase clouds. Since the saturation water vapor pressure over water is higher than that over ice, ice crystals gain mass by vapor deposition at the expense of the supercooled droplets that lose mass by evaporation (Wegener 1911). Owing to the relatively low ice crystal number concentration but high droplet concentration in clouds, many droplets surround each ice crystal. As a result, the droplets evaporate with the resulting water vapor being deposited onto crystals to form precipitating particles, which is called the Bergeron (1935) precipitation process.

Consider two cold clouds that have the same structure except that one has IN but the other not. Since supercooled droplets exist at temperatures from 0 to $-40^{\circ} \mathrm{C}$, they are thermodynamically unstable. They remain in a liquid state in the cloud without IN. In the other cloud with IN, however, some supercooled droplets freeze due to heterogeneous 
nucleation and others evaporate with the resulting water vapor being deposited onto activated IN and ice crystals. This sensitivity of clouds to IN, which is referred to here as the Findeisen (1938) colloidal instability, makes it possible for IN to dramatically affect clouds and radiation (Jiang et al. 2000; Zeng et al. 2008b, 2009). Since the Bergeron process (or Findeisen instability) is one of the dominant precipitation processes in stratiform mixed-phase clouds, it leads to IN having a strong effect on stratiform clouds (e.g., Jiang et al. 2000).

\section{b. Effect of IN on stratiform clouds}

Recent long-term CRM simulations revealed that an increase in IN concentration ${ }^{1}$ brings about a decrease in bulk precipitation efficiency $(\mathrm{PE})$ and thus an increase in upper tropospheric (UT) cloud ice content (Zeng et al. 2009). This effect of IN on PE can be illustrated with a two-layer model. First, consider a single ice crystal that grows by vapor deposition and riming in a mixed-phase region. Its depositional growth rate, measured with an increase in scale (e.g., equivalent radius), is inversely proportional to its scale, whereas the riming growth rate is directly proportional to its scale. Hence, the Bergeron process narrows the ice crystal spectrum while riming broadens it. Since the MarshallPalmer distribution of precipitating particles (Pruppacher and Klett 1997) implies the

\footnotetext{
${ }^{1}$ Owing to the importance of supercooled droplets in the effect of increased IN on radiative forcing (see Fig. 11 for a summary), only the increase in IN concentration in the mixed-phase region and its effects are modeled and discussed in the present paper and in previous ones (Zeng et al. 2008b, 2009).
} 
existence of large particles, its widespread occurrence indicates that riming is important in mixed-phase precipitation in the atmosphere.

Second, consider a mixed-phase cloud with a cloud top temperature warmer than $40^{\circ} \mathrm{C}$. Suppose that all of the ice crystals in the cloud have the same size and the cloud is divided vertically into two layers. Given an increase in IN concentration in the upper layer, new ice crystals will first form on the activated IN and then begin to approach the original ones in size via the Bergeron process, although they remain smaller than the original ones. As a result, the precipitating ice content and thus PE increases correspondingly (neglecting riming, Graupel riming is quite effective especially when graupel particles are large).

After riming starts to become important, the new crystals cannot approach the original ones in size. Instead, their difference in size becomes larger and larger because the riming growth rate is directly proportional to crystal scale. Since the new (or smaller) crystals grow at the expense of supercooled droplets, cloud water content decreases and therefore the growth rate of the original (or larger) crystals slows. In other words, the original crystals would decrease in size with increasing IN concentration in the upper layer. Once the original crystals fall into the lower layer, the conversion rate of cloud water to precipitating ice due to riming would be reduced there as a result of the increased IN in the upper layer.

Suppose that the IN concentration follows the formula of Fletcher (1962). Thus, the increase in IN concentration in the lower layer is much smaller than that in the upper one. As a result, the change in precipitating ice formation is quite small in the lower layer if no precipitating ice particles fall in from the upper layer, but large if precipitating ice 
crystals fall in. Since the crystal growth rate due to the riming (or Bergeron) process is directly (or inversely) proportional to crystal scale, the impact of IN on precipitation formation via the riming process is much greater than it is for the Bergeron in the lower layer. As a net result, the bulk PE in the mixed-phase cloud decreases with increasing IN concentration.

In summary, with increasing IN concentration, small precipitating crystals (or snow content in the CRM) increase in population while large precipitating particles (or graupel content in the CRM) decrease. Correspondingly, the Bergeron process becomes stronger but the riming becomes weaker, resulting in a net decrease in bulk PE. All of the effects of increased IN on snow, graupel and bulk PE are evident in the long-term CRM simulations of Zeng et al. (2008b, 2009).

IN can affect UT ice and radiation via the supercooled droplets in stratiform clouds. Consider, for example, a stratiform mixed-phase cloud in the middle troposphere. It is usually embedded in a synoptic system (e.g., a cold front; Matejka et al. 1980) with largescale upward motion. Once it dissipates, its residue (e.g., cloud drops) is transported by large-scale upward motion into the upper troposphere where it forms ice clouds. Since IN can affect stratiform mixed-phase clouds in the middle troposphere, they can modulate UT ice and thus radiation on a long timescale.

\section{c. Effect of IN on convective clouds}

IN can also affect UT ice and radiation via the supercooled droplets in convective clouds. They work similarly but in a complicated way, because there are strong updrafts and thus high liquid water content in the clouds. Figure 1 displays a schematic cloud 
cluster (Zipser 1969; Houze 1977) to illustrate how IN affect radiation. Ice crystals and supercooled droplets coexist in a mixed-phase region in the middle troposphere. Since IN concentration influences ice crystal concentration, it can affect the Bergeron and riming processes in the region, which in turn can affect the UT cirrus anvil through rising air currents.

The precipitation formation in convective clouds, just as that in stratiform ones, decreases with increasing IN concentration. Since IN affect the Wegener and Bergeron processes directly but graupel riming indirectly via the amount of available supercooled droplets, the decrease in precipitation formation from increased IN becomes smaller when the supercooled droplet content is higher. Consider, for example, an air parcel in a convective cloud moving upward starting at the bottom of the lower mixed-phase region. Numerous graupel particles that formed in the upper region, as discussed in the preceding subsection, fall into the parcel and rime the supercooled droplets. If the IN concentration increases, these intruding graupel particles decrease in size and the conversion rate of cloud water to precipitating ice (or PE) decreases significantly.

When the parcel rises slantwise, its temperature falls. As a result, many of the increased IN become activated and grow to large ice crystals via the Bergeron and riming processes, although they are still smaller than the previous intruding particles. Since the parcel has high cloud water content, the new, yet large crystals rime cloud water efficiently, partially offsetting the preceding effect of the increased IN on cloud water. As a result, the effect of IN on bulk PE in convective clouds is weaker than that in stratiform clouds. This difference in the IN effect between convective and stratiform clouds is supported by the CRM simulations of Zeng et al. (2008b, 2009). The modeled bulk PE in 
middle latitudes, for example, decreases more with increasing IN concentration in spring than in summer (Zeng et al. 2009) because the stratiform precipitation percentage in spring is larger than that in summer.

\section{d. The ensemble effect of IN on radiation}

The ensemble effect of IN on radiation relies on cloud ensembles as well as individual cloud structures. Clouds are usually classified into convective and stratiform (Churchill and Houze 1984; Nesbitt et al. 2006). Since the effect of IN on PE is relatively strong in stratiform clouds but weak in convective ones, the ensemble effect of IN on radiation depends on the ratio between the stratiform and convective cloud amounts, which is formulated next.

Consider a cloud ensemble that consists of two kinds of clouds: stratiform and convective. Let $N_{s}$ and $N_{c}$ denote the stratiform and convective cloud amounts, respectively. Thus, the increase in downward radiative flux from doubling the IN concentration can then be written

$$
\Delta F_{i}=\Delta f_{s i} N_{s}+\Delta f_{c i} N_{c},
$$

or

$$
\Delta F_{i}=\left(N_{s}+N_{c}\right)\left[\Delta f_{c i}+\left(\Delta f_{s i}-\Delta f_{c i}\right) F_{s}\right],
$$

where the fraction of stratiform clouds $F_{s}=N_{s} /\left(N_{s}+N_{c}\right) ; \Delta f_{s i}$ and $\Delta f_{c i}$ represent the increases in the radiative flux from doubling the IN concentration when $N_{s}=1$ and $N_{c}=1$, respectively. As shown in (2.1), the fraction of stratiform clouds is important in the ensemble effect of IN on radiation because $\Delta f_{s i}$ is much larger than $\Delta f_{c i}$ in magnitude. 
Strictly speaking, $N_{s}$ and $N_{c}$ represent the amounts of stratiform and convective mixedphase clouds, respectively. Since mixed-phase clouds usually precipitate efficiently, the fraction of stratiform clouds in (2.1) has the same meridional tendency as the fraction of stratiform precipitation, although the two fractions differ in quantity to some extent. Next, TRMM observations are used to analyze the meridional tendency in stratiform precipitation fraction.

\section{e. Climatology of stratiform precipitation fraction}

Belts of climatic zones imply that cloud properties (e.g., the stratiform precipitation fraction) vary mainly with latitude instead of longitude. In this subsection, 10 years of TRMM data are analyzed to identify meridional and seasonal variations in stratiform precipitation fraction.

A precipitation radar (PR) was included on the TRMM satellite to provide threedimensional maps of convective and stratiform clouds. In addition, a TRMM microwave imager (TMI), a multi-channel passive microwave sensor, was also included to provide rainfall information (Simpson et al. 1988). These two instruments have performed successfully for over ten years. Their coverage extends from approximately $37^{\circ} \mathrm{S}$ to $37^{\circ} \mathrm{N}$.

The latitudinal stratiform precipitation fractions were computed using a gridded $(0.5 \mathrm{x}$ 0.5 degree horizontal resolution) rain product based on TRMM satellite data (i.e., 3G68). The product includes rainfall information derived from the TMI and the PR. The TMI rain retrieval algorithm (Kummmerow et al. 2001; Olson et al. 2006) uses a Bayesian approach to match observed brightness temperatures with a database of CRM-simulated 
hydrometeor profiles via a radiative transfer model. A combination of techniques using polarization information and horizontal textures (i.e., gradients) are used to separate the rainfall into its convective and stratiform components (Olson et al. 2001). The PR rain retrieval algorithm (Iguchi and Meneghini 1994; Iguchi et al. 2000) accounts for the effects of attenuation. Horizontal reflectivity gradients (Steiner et al. 1995) as well as bright band information are used to separate the PR rainfall into its convective and stratiform components. The stratiform precipitation fraction as a function of latitude is calculated by summing the total stratiform rain amount in each 0.5 degree latitude belt and dividing by the total rain amount over the same area. Average values were computed over a 10-year period ranging from 1 January 1998 through 31 December 2007.

Figure 2 displays the mean PR- and TMI-derived stratiform precipitation fractions against latitude. Since atmospheric stability increases with latitude, the fractions become larger at higher latitude and approach $100 \%$ over arctic regions (Curry et al. 1996). Hence, dashed lines are introduced in the figure to show the meridional tendency beyond $37^{\circ}$.

Generally speaking, the PR- and TMI-derived fractions vary similarly with latitude. Since the PR beam can penetrate into clouds and thus provide bright band information to separate convective and stratiform regions, the PR-derived stratiform precipitation fraction makes more sense in Eq. (2.1) than the TMI-derived. The PR-derived fraction, as shown in Fig. 2, changes little between $20^{\circ} \mathrm{S}$ and $20^{\circ} \mathrm{N}$ but increases significantly with latitude in the subtropics and middle latitudes.

Figure 3 displays the PR- and TMI-derived stratiform precipitation fractions versus latitude for all seasons. The fractions are relatively large in winter and spring and 
relatively small in summer and fall. In particular, the PR-derived fraction in spring is close to that in winter in the northern hemisphere and is much larger than that in summer and fall in middle latitudes.

Since the IN effect is relatively strong in stratiform clouds but weak in convective ones, $\Delta f_{s i}$ is much larger than $\Delta f_{c i}$ in magnitude. For a given value of $\left(\Delta f_{s i}-\Delta f_{c i}\right)$, the ensemble effect of IN on radiation relies on the stratiform cloud fraction and therefore varies with latitude and season via the fraction. Based on Figs. 2 and 3 as well as Eq. (2.1), two results are inferred: (1) the ensemble IN effect varies little with latitude in the Tropics but significantly in middle and high latitudes and (2) the effect is stronger in winter and spring than in summer and fall especially in the northern hemisphere.

\section{Numerical experiments}

In this section, CRM simulations are carried out to confirm and quantify the proposed meridional tendency in the IN effect. It consists of four subsections. The first one introduces field campaigns as well as their large-scale forcing data. The second describes the model structure. The third presents CRM simulations at various latitudes, focusing on the modeled meridional variation in stratiform precipitation fraction. The last one confirms and quantifies the proposed meridional tendency in the IN effect.

\section{a. Field campaigns}

Ten field campaigns conducted at various latitudes were used to obtain large-scale forcing to drive long-term CRM simulations as well as cloud observations to evaluate the modeled cloud ensembles. These field campaigns were scattered over the Tropics and 
middle latitudes; their geographic locations are shown in Fig. 4. The campaigns were chosen primarily to show the insensitivity of radiative forcing (or the net radiative flux at the TOA) to IN in the Tropics and the rest to show the sensitivity of radiative forcing to IN outside the Tropics.

Table 1 summarizes the field campaigns and their CRM simulations. In addition to the campaigns studied in Zeng et al. (2009), the NAME (North American Monsoon Experiment) is added in this study to explore the effects of IN in the subtropics, because the stratiform precipitation fraction increases significantly with latitude in the region (see Fig. 2).

NAME was centered at $26^{\circ} \mathrm{N}$ and $107^{\circ} \mathrm{W}$ (Johnson et al. 2007). It provided average large-scale forcing over the land portion of the NAME Enhanced Budget Array (EBA) from 0000 UTC 7 July through 1800 UTC 15 August 2004 (Ciesielski and Johnson 2008; Ciesielski et al. 2009). The forcing data were derived from six-hourly observations at five sounding sites located along the perimeter of the EBA polygon and included a humidity correction (Ciesielski et al. 2009). This forcing data is used to drive 40-day CRM simulations to determine the effect of IN in the subtropics.

In addition to NAME, large-scale forcing data from six tropical field campaigns were used to drive CRM simulations to establish the effect of IN in the Tropics. The six campaigns include the Tropical Ocean Global Atmosphere (TOGA) Coupled OceanAtmosphere Response Experiment (COARE) conducted in 1992 and 1993, the 1999 Kwajalein Experiment (KWAJEX), the 1974 Global Atmospheric Research Program's Atlantic Tropical Experiment (GATE), and the 2006 Tropical Warm Pool - International Cloud Experiment (TWP-ICE). The 1998 South China Sea Monsoon Experiment 
(SCSMEX) that was conducted over the northern (NESA) and southern (SESA) enhanced sounding array polygons was also included.

Three field campaigns were used to provide large-scale forcing to drive CRM simulations in middle latitudes. The campaigns were conducted at the Southern Great Plains (SGP) site set up by the Atmospheric Radiation Measurement (ARM) Program. The three campaigns are referred to here as ARM-SGP-97, 00 and 02, which occurred in the summer of 1997, spring of 2000 and summer of 2002, respectively. All of the field campaigns except for NAME are summarized in Zeng et al. (2009).

\section{b. Model description}

The Goddard Cumulus Ensemble model is a CRM (Tao and Simpson 1993; Tao et al. 2003). Here it is used to simulate the effects of $\mathrm{IN}$ on clouds and radiation. The model is non-hydrostatic and anelastic. It parameterizes subgrid-scale (turbulent) processes with a scheme based on Klemp and Wilhelmson (1978) and Soong and Ogura (1980), and incorporates the effects of both dry and moist processes on the generation of subgridscale kinetic energy. It uses a three-class ice formulation for cloud microphysics based on the scheme of Rutledge and Hobbs (1984) with some modification (Lang et al. 2007; Zeng et al. 2008b). The model includes the sedimentation of cloud ice (Starr and Cox 1985) to better simulate clouds in the upper troposphere. It calculates all scalar variables (temperature, water vapor, and all hydrometeors) with a positive definite advection scheme (Smolarkiewicz and Grabowski 1990).

The model takes account of both emission and absorption of infrared radiation and both scattering and absorption of solar radiation. It divides the entire spectrum of infrared 
radiation into nine bands to compute infrared fluxes, and thus models the effects of water vapor and hydrometeor species on longwave fluxes (Chou et al. 1995, 1999). It also divides the entire spectrum of solar radiation into 11 bands (i.e., seven bands in the ultraviolet region, one band in the photosynthetically active radiation region, and three bands in the near infrared region) to compute solar fluxes, and thus models the effects of water species on shortwave fluxes (Chou and Suarez 1999). This radiation scheme is summarized in Tao et al. $(1996,2003)$, and has been used to assess cloud-radiation interaction (Tao et al. 1996).

The model has five prognostic hydrometeor variables: the mixing ratios of cloud water, rainwater, cloud ice, snow and graupel. The IN concentration is introduced into the parameterization of the Bergeron process as an input factor (Zeng et al. 2008b, 2009). Since the IN concentration changes the cloud-ice crystal concentration via heterogeneous nucleation, it quickly changes the cloud-ice crystal spectrum because smaller crystals grow faster via vapor deposition. Hence, the Bergeron process or the conversion rate of cloud ice to snow due to vapor deposition is connected to IN concentration by (Zeng et al. 2008b, 2009)

$$
\max \left[2 a_{1}\left(3 q_{i}-m_{I 50} \rho^{-1} \mu N_{i}\right) m_{I 50}^{a_{2}-1}, 0\right]
$$

and the Wegener process or the conversion rate of cloud water to cloud ice is connected to IN concentration by

$$
\frac{2}{\left(a_{2}+1\right)\left(a_{2}+2\right)}\left[3 a_{2} q_{i}+\left(1-a_{2}\right) m_{I 50} \rho^{-1} \mu N_{i}\right] a_{1} m_{I 50}^{a_{2}-1},
$$

where $N_{i}$ is the number concentration of active ice nuclei, $q_{i}$ the mixing ratio of cloud ice, $a_{1}$ and $a_{2}$ the temperature-dependent parameters in the Bergeron process (Koenig 1971), $\rho$ the air density, the mass of an ice crystal $50 \mu \mathrm{m}$ in diameter $m_{I 50}=4.8 \times 10^{-7} \mathrm{~g}$, and the 
ice particle enhancement factor due to a riming-splintering mechanism (Hallett and Mossop 1974) and others $\mu=1.2$ in mid-latitudinal clouds. Expressions (3.1) and (3.2) follow the cgs (centimeter-gram-second) system, and the two conversion rates have units of $\mathrm{g} \mathrm{g}^{-1} \mathrm{~s}^{-1}$.

Since the ice crystal concentration is much lower than water droplet concentration in the mixed-phase region, the air is almost saturated with respect to water (e.g., Korolev and Mazin 2003). Hence, the diffusional growth of ice crystals is independent of water droplet concentration. Therefore, (3.1) and (3.2) are independent of cloud water content.

The model employs the formula of Fletcher (1962) to compute the active IN concentration in clouds as a function of air temperature $T$ or

$$
N_{i}=n_{0} \exp \left[\beta\left(T_{0}-T\right)\right]
$$

where $n_{0}$ and $\beta$ are constant, and $T_{0}=273.16 \mathrm{~K}$. Substituting (3.3) into (3.1) and (3.2) yields the two expressions for the Bergeron and Wegener processes, respectively. Obviously, the expressions vary with $\mu n_{0}$ and $\beta$, where $\mu$ and $n_{0}$ are not separated.

To explore the effect of $\mathrm{IN}$ on clouds and radiation, the model is run with differing amounts (i.e., categories) of IN concentration (see Table 2) for a given large-scale forcing. The ice crystal number concentration, generally speaking, increases as the IN category changes from I to VI.

Since the model represents clouds explicitly (Moncrieff et al. 1997; Randall et al. 2003), it is used to simulate clouds with prescribed large-scale forcing derived from observational data. The simulations follow the same setup as has been used in previous studies (e.g., Grabowski et al. 1998; Petch and Gray 2001; Blossey et al. 2007; Zeng et al. 2007,2008 b, 2009) of this type. All of the simulations carried out are three-dimensional 
(3D), using a $1 \mathrm{~km}$ horizontal resolution and a vertical resolution that ranges from $42.5 \mathrm{~m}$ at the bottom to $1 \mathrm{~km}$ at the top. The model uses $256 \times 256 \times 41$ gridpoints and a time step of 6 seconds for integration.

\section{c. CRM simulations at various latitudes}

CRM simulations for the ten field campaigns are carried out to address the IN effect versus latitude. Different IN categories (see Table 1) are tested for each campaign. Most of the simulations are detailed in Zeng et al. (2009). Here, four additional CRM simulations for NAME are introduced to bridge the gap between the Tropics and middle latitudes. The four simulations follow the same model setup as those in Zeng et al. (2009) except for the following details. The simulations are driven with the large-scale forcing derived from the NAME observations (Ciesielski et al. 2009), starting at 0000 UTC 7 July 2004 and lasting for 40 days. Since it is difficult to get accurate mean surface fluxes over a land region for long-term CRM simulations (Zeng et al. 2007), the simulations relax the temperature and humidity at the lowest model level to the observed values with a timescale of ten minutes. This relaxing timescale is so short that the model results are not sensitive to the imposed surface fluxes.

The four simulations use IN categories II to $\mathrm{V}$ (see Table 2), respectively. The modeled precipitation rate and precipitable water are sensitive to IN concentration (figure omitted) just as in the other CRM simulations (Zeng et al. 2009). To compare precipitation formation in the stratiform mixed-phase region with that in the convective one, a contoured frequency with altitude diagram (CFAD; Yuter and Houze 1995) of vertical velocity in the mixed-phase region is computed for the NAME simulation that 
uses IN category IV (figure omitted), showing that small vertical velocities are far more prevalent than large ones in the mixed-phase region.

Since the variables $q_{i}$ and $q_{c} q_{g}$ are directly proportional to the precipitation formation rates due to the Bergeron and riming processes, respectively, Fig. 5 displays their averages as functions of pressure and vertical velocity, where $q_{i}, q_{c}$ and $q_{g}$ are the mixing ratios of cloud ice, cloud water and graupel, respectively. The values in the figure are computed by averaging $q_{i}$ and $q_{c} q_{g}$ horizontally in the same mixed-phase region. As shown in Fig. 5, graupel riming is relatively important in the regions with large vertical velocity (or convective precipitation). In contrast, the Bergeron process is important in the regions with small vertical velocity (or stratiform precipitation) because the frequency of low vertical velocity is relatively high.

The NAME simulations are consistent with the others in duplicating the shift of precipitation from convective to stratiform with increasing latitude. Figure 6 displays the averages of $q_{i}$ and $q_{c} q_{g}$ as functions of pressure and vertical velocity for two CRM simulations: one over a tropical region (i.e., the GATE simulation with IN category $\mathrm{V}^{2}$ ) and the other over a mid-latitudinal region (i.e., the ARM-SGP-00 simulation with IN category II). The tropical simulation, in contrast to the mid-latitudinal one, has strong

${ }^{2}$ The proper IN category (or $\mu N_{i}$ ) for each campaign is chosen so that its corresponding CRM simulations are close to the field observations (Zeng et al. 2009; also see section 3.e). In the present paper, $N_{i}$ is not distinguished from $\mu$. In fact, $\mu$ decreases significantly with increasing latitude. Its magnitude in tropical clouds is about $10^{3}-10^{4}$ times that in mid-latitudinal clouds, which is discussed elsewhere. 
graupel riming especially at a pressure of $420 \mathrm{hPa}$ and vertical velocity of $25 \mathrm{~m} / \mathrm{s}$, which indicates that graupel riming is more important in tropical precipitation.

Contrasting Figs. 5 and 6 shows that graupel riming is most important in the GATE simulation, less so for NAME, and the least for ARM-SGP-00, which makes physical sense because, latitudinally, NAME is located between GATE and ARM-SGP. Table 3 summarizes the modeled stratiform precipitation percentages in GATE, NAME and ARM-SGP-00. It shows that the modeled stratiform precipitation fraction becomes larger at higher latitude, which agrees with the TRMM observations (or Fig. 2). Hence, it is expected that CRM simulations at various latitudes can capture the proposed meridional variation in the IN effect.

\section{d. The IN effect at different latitudes}

IN affect clouds and radiation via supercooled droplets (see Sections 2.b and 2.c). An increase in IN concentration brings about a decrease in bulk PE and thus an increase in UT cloud ice content (Zeng et al. 2009). Figure 7 summarizes the modeled effects of IN on UT cloud ice content and radiation at various latitudes. Since the mixed-phase region is observed at temperatures between 0 and $-40^{\circ} \mathrm{C}$ (and most often at the warmer end of the range; e.g., Pruppacher and Klett 1997; DeMott et al. 2003), the figure uses the IN concentration at $-10^{\circ} \mathrm{C}$ as an index to represent the concentration of active IN in clouds.

Figure 7 displays the modeled UT cloud ice content against the IN concentration at $10^{\circ} \mathrm{C}$ over the ten field campaigns. The content increases with $\mathrm{IN}$ concentration. The figure also displays the modeled downward net radiative flux at the TOA versus the IN concentration. The flux increases first and then decreases considerably with increasing IN 
concentration in mid-latitudes. In contrast, the flux changes little with IN concentration in the Tropics.

This differing IN effect can be understood with a simple model. Consider an opticallythin UT cirrus cloud in a clear sky. The cloud is so thin that it functions like a subvisual cirrus cloud. Thus, its solar reflection is quite small while its infrared absorption is relatively large. When its ice content increases, its solar reflection increases slower than its infrared absorption. As a result, the downward net radiative flux at the TOA increases correspondingly. This sensitivity of the TOA radiative flux to UT ice content explains the mid-latitudinal phenomenon that the TOA flux, when the IN concentration or UT ice content is low, increases with increasing IN concentration.

If the ice content continues to increase until the infrared absorption is close to one but the solar reflection is still far below one, the ice content would be high. If the content increases further, the infrared absorption increases little because of its ceiling, whereas the solar reflection can increase a lot. As a result, the downward net radiative flux at the TOA decreases correspondingly, which explains the mid-latitudinal phenomenon that the TOA flux, when the IN concentration or UT ice content is high, decreases with increasing IN concentration.

In fact, the TOA radiative flux usually changes more moderately compared to those in the preceding two extreme cases. When the IN concentration or UT ice content is relatively low, the TOA flux increases with increasing IN concentration. When it is high, the TOA flux decreases. Of course, when it is moderate, the TOA flux changes little, which explains the insensitivity of the TOA radiative flux to IN concentration in the Tropics. 
e. Meridional variation in radiative forcing from doubling the current IN concentration

IN concentration varies significantly from one region to another (e.g., Fletcher 1962; Pruppacher and Klett 1997; DeMott et al. 2003). Given in-situ active IN concentrations over the field campaigns, the IN effect from doubling the current IN concentration can be determined based on Fig. 7. However, no direct IN observations are available from the field campaigns. To diagnose an in-situ IN concentration over a region, the model was assigned different IN concentrations for different simulations. If a cloud simulation can be made to match the associated observations, then its assigned IN concentration should correspond to the in-situ $\mathrm{IN}$ concentration over that region.

To determine the average IN concentration in mid-latitudinal clouds, ARM-SGP simulations using different IN concentrations are compared with field observations first. Figure 8 displays the biases in the modeled upward infrared flux at the TOA, precipitable water and surface precipitation rate against the IN concentration at $-10^{\circ} \mathrm{C}$. Corresponding zero biases indicate that the in-situ active IN concentration is $\sim 3 \times 10^{-2} \mathrm{~m}^{-3}$ at $-10^{\circ} \mathrm{C}$ in mid-latitudinal clouds. This low IN concentration is consistent with previous observations $^{3}$ (e.g., Rutledge and Hobbs 1984) because in many mid-latitudinal

${ }^{3}$ A typical IN concentration measured outside of mid-latitudinal clouds is 1 to $10 \mathrm{~L}^{-1}$ at temperatures from -17 to $-50^{\circ} \mathrm{C}$ (DeMott et al. 2003; Richardson et al. 2007). It is much higher than the diagnosed IN concentration of $\sim 3 \times 10^{-5} \mathrm{~L}^{-1}$ at $-10^{\circ} \mathrm{C}$ in mid-latitudinal clouds, even after being adjusted to the same temperature. Since the measured ambient IN concentration cannot explain the lack of ice crystals in many mid-latitude continental clouds with cloud top temperatures below $0^{\circ} \mathrm{C}$ (e.g., Paluch 1979; Blyth et al. 1988), it 
continental cumulus clouds, for example, no ice crystals have been found even with a cloud top temperature of $-20^{\circ} \mathrm{C}$ (e.g., Paluch 1979; Blyth et al. 1988).

Since the diagnosed IN concentration is between category I and II, the ARM-SGP simulations with categories I and II are used to determine the IN effect from doubling the current IN concentration in middle latitudes. The increase in a variable $F$ (e.g., a radiative flux) from doubling the IN concentration is computed as

$$
\frac{F^{I I}-F^{I}}{\ln \left(N_{i}^{I I} / N_{i}^{I}\right)} \ln 2=\frac{F^{I I}-F^{I}}{\log _{2}\left[\left(\mu N_{i}^{I I}\right) /\left(\mu N_{i}^{I}\right)\right]},
$$

where a superscript indicates an IN category used in a CRM simulation. Using (3.4), the increases in the upward solar and infrared fluxes at the TOA from doubling the IN concentration are first obtained from ARM-SGP-97, -00 and -02 and then displayed against latitude in Fig. 9. Similarly, the increases in the downward net radiative flux at the TOA from doubling the IN concentration are displayed in Fig. 10.

The preceding procedure for determining the current IN effect is applied to cases over the Tropics and subtropics in turn. The modeled precipitation rate and precipitable water are compared with the observed over the tropical campaigns, showing that the simulations with category V best mimic the observations (Zeng et al. 2009). Recently, TRMM PR observations over KWAJEX (Matsui et al. 2009) and radar observations over TWP-ICE (to be reported later) were compared with modeled cloud ensembles, supporting the conclusion of Zeng et al. (2009) that the tropical simulations with IN

must be different from the active IN concentration in clouds. Physically this makes sense because cloudy and ambient parcels move to their positions along different trajectories and therefore should have different rates (or "amounts") of nucleation. 
category $\mathrm{V}$ resemble observations (see footnote 2 for the role of $\mu$ ). Hence, the CRM simulations with IN categories IV and $\mathrm{V}$ over the tropical campaigns (i.e., SCSMEX/NESA, TWP-ICE, GATE, KWAJEX, SCSMEX/SESA and TOGA-COARE) are used to determine the increases in the radiative fluxes from doubling the current IN concentrations in the Tropics. Since NAME is located between the ARM-SGP and tropical campaigns, the two NAME simulations with IN categories II and IV are used to determine the increases in the radiative fluxes from doubling the IN concentration in the subtropics.

Figures 9 and 10 summarize the effect of doubled IN on radiation at different latitudes. The upward solar and infrared fluxes at the TOA increase and decrease with doubled IN concentrations, respectively, which is attributed to the increase in UT ice content with increasing IN concentration. Moreover, the increase in the solar flux is close to the decrease in the infrared one in the Tropics, whereas the former is much smaller than the latter in middle latitudes. The differing response between the Tropics and middle latitudes makes physical sense because the in-situ UT ice content is much higher in the Tropics than in middle latitudes (see Fig. 7).

Figure 10 shows the increase in radiative forcing (or the downward net radiative flux at the TOA) from doubling the current IN concentration against latitude, which is obtained from the CRM simulations over the ten field campaigns. Based on the meridional tendency in stratiform precipitation fraction (see Fig. 2), two lines are introduced to fit the simulated increase in spring and summer, respectively. As shown in the figure, the current downward net radiative flux at the TOA increases significantly with IN concentration in mid-latitudes but not in the Tropics. Furthermore, the net flux is more 
sensitive to IN concentration in spring than in summer. This differing IN effect in different seasons is consistent with that at different latitudes, because stratiform precipitation fraction is larger in spring than in summer (see Figs. 2 and 3).

\section{Increasing IN concentration and global warming}

\section{a. Meridional tendency of the IN-induced warming}

IN affect global warming via the net radiative flux at the TOA. Consider an increase in IN concentration. It results in a $\overline{\Delta F}$ increase in global mean (downward) net radiative flux at the TOA via clouds. It also results in an increase in the equivalent blackbody (or surface) temperature of the globe from $\bar{T}$ to $\bar{T}+\overline{\Delta T}$. Since the Earth maintains radiative equilibrium on a climatic scale ${ }^{4}$,

$$
\overline{\Delta F}=\sigma\left(\bar{T}+\overline{\Delta T}^{4}-\sigma \bar{T}^{4}\right.
$$

where $\sigma$ is the Stefan-Boltzmann constant, which yields

$$
\overline{\Delta T}=\lambda \overline{\Delta F}
$$

where $\lambda=\left(4 \sigma \bar{T}^{3}\right)^{-1}$. The value of $\lambda$ is around $0.25 \mathrm{~K}\left(\mathrm{~W} \mathrm{~m}^{-2}\right)^{-1}$ (Charney 1979).

${ }^{4}$ The effective thermal capacity of the Earth's surface is not important for global warming. Consider a linear model $C d \overline{\Delta T} / d t=\overline{\Delta F}-4 \sigma \bar{T}^{3} \overline{\Delta T}$, where $t$ is time and $C$ is the effective thermal capacity of the Earth's surface that warming influences. For a given forcing $\overline{\Delta F} \sim \sin (\omega t)$ where $\omega$ is angular frequency, the forced mode is $\overline{\Delta T} \sim\left[4 \sigma \bar{T}^{3} \sin (\omega t)-C \omega \cos (\omega t)\right]\left[(C \omega)^{2}+\left(4 \sigma \bar{T}^{3}\right)^{2}\right]^{1}$. When $4 \sigma \bar{T}^{3} / C \omega>>1$, the forced mode degenerates into Eq. (4.1), and therefore the thermal capacity becomes negligible. 
Since radiative equilibrium approximately describes a regional thermal balance (Manabe and Strickler 1964; Emanuel et al. 1994), Eq. (4.2) can be used to estimate the temperature change for a given regional increase in IN concentration. Supposing that $\left.\lambda=0.25 \mathrm{~K}_{(\mathrm{W} \mathrm{m}}^{-2}\right)^{-1}$ (Charney 1979), the vertical axis of Fig. 10 also scales to the increase in surface temperature from doubling the IN concentration.

To compare the IN-induced warming with the $\mathrm{CO}_{2}$-induced one, Figure 10 displays the increase in the net radiative flux (or surface temperature) when the atmospheric $\mathrm{CO}_{2}$ concentration is increased from a pre-industrial value of about $280 \mathrm{ppm}$ to $379 \mathrm{ppm}$ in 2005 (IPCC 2007, p. 25). Clearly, the surface warming from doubling the IN concentration is much stronger than that from the anthropogenic $\mathrm{CO}_{2}$ in the subtropics and middle latitudes, and a stronger warming is expected in high latitudes.

\section{b. Geographic distribution of IN sources}

The IN-induced warming varies geographically because it depends on two factors: the radiative effect from doubling the IN concentration and the actual increase in IN concentration. Since the $\mathrm{CO}_{2}$-induced warming is horizontally uniform, the IN-induced warming can be identified from global warming if it varies in space and time similar to what is observed. Next, the geographic and seasonal variations in IN-induced warming are inferred and contrasted with observations.

IN (such as dust, biological and soot particles) are usually generated by natural and human activity over continents (Pruppacher and Klett 1997, DeMott et al. 2003; Möhler et al. 2007; Phillips et al. 2008). Assuming that a significant increase in IN production is due to global desertification (Schlesinger 1990), a large increase in IN concentration 
would arise over continents but not over oceans, which could then lead to a strong warming response over continents but not over oceans. Because the net radiative flux at the TOA is insensitive to IN concentration in the Tropics, the warming is weaker over the equator but stronger away from the equator. This saddle-shaped warming pattern resembles the observed, such as that over the African continent and the American and Asian-Australian regions (IPCC 2007, p. 37). As a special case, IN generated in Asia and Australia are usually transported by westerly winds over the Pacific such that their increase brings about a saddle-shaped warming pattern over the western and central Pacific (IPCC 2007, p. 37).

In addition, localized areas of intense desertification can lead to strong local increases in IN production and correspondingly to localized areas of strong warming. Deforestation and desertification near the borders of the Sahara and Gobi deserts, for example, have increased IN in those regions, which is well correlated with the strong warming that's been observed over northern Africa and northeastern China (IPCC 2007, p. 37), respectively. The central Sahara and western Australia, due to their sparse flora, provide little room for further desertification (or no increase in IN production), which results in relatively weak warming in those regions (IPCC 2007, p. 37).

Besides global desertification, industrialization (Ramanathan et al. 2007) has increased IN concentrations (e.g., Plaude et al. 2007) that can contribute to global warming. Consider, for example, a horizontally uniform increase in IN concentration due to industrialization. Owing to the meridional tendency in the IN effect, it can bring about a stronger warming at higher latitudes, which matches the observation that the strongest warming has occurred in the northern arctic region over the past 100 years (IPCC 2007, 
p. 37). Similarly, heavy industrial IN production over Europe corresponds to the observed strong warming there from 1979 to 2005 (IPCC 2007, p. 37).

The IN-induced warming has a seasonal variation, too. Since the current net radiative flux in mid-latitudes would increase more with IN concentration in spring than in summer, a similar increase in IN concentration can bring about a stronger warming in winter and spring but a weaker one in summer and fall. This IN effect resembles the observations from the last 30 years that the greatest warming has occurred in winter and spring (IPCC 2007, p. 37). All of the preceding scenarios wherein strong warming coincides with increased IN production suggest that IN may have contributed to global warming especially in middle and high latitudes.

\section{Conclusions and discussion}

The total surface temperature increase from the period 1850 to 1899 to the period 2001 to 2005 is $0.76^{\circ} \mathrm{C}$ (IPCC 2007, p. 36), and the contribution of anthropogenic $\mathrm{CO}_{2}$ to the net radiative flux at the TOA is $1.66 \mathrm{~W} \mathrm{~m}^{-2}$ in 2005 (IPCC 2007, p. 32). Given $\lambda=0.25$ $\mathrm{K}\left(\mathrm{W} \mathrm{m}^{-2}\right)^{-1}$ in (4.2) (Charney 1979), the increase in $\mathrm{CO}_{2}$ over the past 150 years brings about a temperature increase of $0.41^{\circ} \mathrm{C}$ or about half of the measured increase. Hence, other candidates may exist that could explain the difference.

Global warming is not horizontally uniform. IPCC (2007, p. 37) summarized its geographic and seasonal variations as follows:

"Surface temperatures over land regions have warmed at a faster rate than over the oceans in both hemispheres. ... The warming in the last 30 years is widespread over the globe, and is greatest at higher northern latitudes. The 
greatest warming has occurred in the northern-hemispheric winter (DJF) and spring (MAM)."

Based on these variations as well as their details (e.g., those over the period 1979 to 2005; IPCC 2007, p. 37), the IN-induced warming can be identified in the observed total warming because the effect of $\mathrm{CO}_{2}$ and other greenhouse gases on global warming is geographically uniform. In reference to the following conclusions, increasing IN concentration is proposed as a candidate for global warming.

- IN affect clouds and radiation significantly via supercooled droplets (see Fig. 11 for a summary). Since the IN effect is relatively strong in stratiform clouds but weak in convective ones, the ensemble effect of IN on radiation depends on the ratio between stratiform and convective cloud amount, which is formulated in (2.1).

- Ten years of TRMM data reveal that the stratiform precipitation fraction increases significantly with latitude beyond the Tropics. The fraction is larger in winter and spring than in summer and fall in middle latitudes, especially in the northern hemisphere.

- CRM simulations at various latitudes show that the increase in the net TOA radiative flux from doubling the IN concentration becomes stronger at higher latitude. Moreover, the increase is larger in spring than in summer in middle latitudes. These modeling results confirm and quantify the meridional tendency of the IN effect derived from the preceding two conclusions.

- It is well-known that IN come from land regions instead of oceans. Thus, global desertification and industrialization over the past decades could bring about a large increase in IN concentration over land regions but not over oceans, although no 
quantitative description is available on the geographic variation of increased IN right now.

Superimposing the last two results yields geographic and seasonal variations of the IN-induced warming (see Section 4.b for details). A general match in the variations between the inferred and observed warming suggests that IN may have contributed positively to global warming especially in middle and high latitudes. With more and more information on geographic variations in IN becoming available in the future, global cloud modeling systems (e.g., the multi-scale modeling framework; Grabowski 2001) can be used to further evaluate the proposed connection between increased IN and global warming.

On the other hand, regional CRM simulations can still be used to quantify the effect of IN on warming over specific geographic regions such as the Arctic. In this study, the effects of IN on warming in the Tropics and middle latitudes are extended into polar regions based on the meridional variation in stratiform precipitation fraction. Due to the poor performance of current CRMs in modeling arctic clouds and precipitation (e.g., clear-sky ice precipitation), no effect of IN on warming has been quantified in the Arctic. Recently, Zeng (2008a) proposed a new precipitation mechanism that works in thin ice clouds and even clear skies. With a proper representation of the mechanism, it is possible to use a CRM to quantify the effect in the Arctic. Since the new mechanism is not as sensitive to IN concentration as the Bergeron and riming processes, it cannot violate the proposed connection between increased IN and warming in the Arctic, although the discussion is still open. 
Furthermore, IN observations and modeling still remain as a challenge. In the present study, the contribution of increased IN to global warming is estimated based on the consistency in geographic variation between the IN-induced and observed warming. Since IN concentration varies highly from one region to another, the estimated contribution is contaminated with uncertainties. Hence, more and better IN measurements are needed as essential information to quantitatively assess the contribution of IN to global warming.

Acknowledgements This research was supported by the NASA Headquarters Atmospheric Dynamics and Thermodynamics Program and the NASA Tropical Rainfall Measuring Mission (TRMM). The research was also supported by the Office of Science (BER), U. S. Department of Energy/Atmospheric Radiation Measurement (DOE/ARM) Interagency Agreement No. DE-AI02-04ER63755. The authors are grateful to Dr. R. Kakar at NASA headquarters and Dr. Kiran Alapaty at DOE/ARM for their support of this research. The research was also supported by NASA and the DOE Atmospheric Radiation Measurement Program at the Stony Brook University. Dr. Xie, working at LLNL, was supported under the auspices of the U. S. Department of Energy/Office of Science, Biological and Environmental Research by the University of California Lawrence Livermore National Laboratory under contract W-7405-Eng-48.

The authors acknowledge the NASA Ames Research Center and the NASA Goddard Space Flight Center for the enormous computer time used in this research. They greatly thank Drs. Richard Johnson and Paul Ciesielski for providing the large-scale forcing data derived from NAME, TOGA-COARE and SCSMEX/SESA. Special thanks are extended 
to Drs. Joanne Simpson, Warren Wiscombe and three anonymous reviewers for their kind comments and suggestions. 


\section{REFERENCES}

Baker, M. B., 1997: Cloud microphysics and climate. Science, 276, 1072-1078.

Bergeron, T., 1935: On the physics of clouds and precipitation. Proc. 5th Assembly U.G.G.I., Lisbon, Portugal, 156-180.

Blossey, P. N., C. S. Bretherton, J. Cetrone, and M. Kharoutdino, 2007: Cloud-resolving model simulations of KWAJEX: model sensitivities and comparisons with satellite and radar observations. J. Atmos. Sci. 64, 1488-1508.

Blyth, A. M., W. A. Cooper and J. B. Jensen, 1988: A study of the source of entrained air in Montana cumuli. J. Atmos. Sci., 45, 3944-3964.

Charney, J. G. 1979: Carbon dioxide and climate: a scientific assessment. Nat. Acad. Sci., Washington, DC. 22 pp.

Chou, M.-D., W. Ridgway, and M.-H. Yan, 1995: Parameterizations for water vapor IR radiative transfer in both the middle and lower atmosphere. J. Atmos. Sci., $\mathbf{5 2}$, 1159-1167.

Chou, M.-D., and M. J. Suarez, 1999: A shortwave radiation parameterization for atmospheric studies. 15, NASA/TM-104606, $40 \mathrm{pp}$.

Chou, M.-D., K.-T. Lee, S.-C. Tsay, and Q. Fu, 1999: Parameterization for cloud longwave scattering for use in atmospheric models. J. Climate, 12, 159- 169

Churchill, D. D. and R. A. Houze Jr., 1984: Development and structure of winter monsoon cloud clusters on 10 December 1978. J. Atmos. Sci., 41, 933-960.

Ciesielski, P. E. and R. H. Johnson, 2008: Diurnal cycle of surface flows during 2004 NAME and comparison to model reanalysis. J. Climate, 21, 3890-3913. 
Ciesielski, P. E., R. H. Johnson, J. Wang, 2009: Correction of humidity biases in Vaisala RS80 sondes during NAME. J. Atmos. Oceanic Technol., DOI: 10.1175/2009JTECHA1222.1.

Curry, J. A., J. L. Schramm, W. B. Rossow and D. Randall, 1996: Overview of arctic cloud and radiation characteristics. J. Climate, 9, 1731-1764.

DeMott, P. J. and Coauthors, 2003: Measurements of the concentration and composition of nuclei for cirrus formation. PNAS, 100, 14655-14660.

Ekman, A. M. L., A. Engstrom, and C. Wang, 2007: The effect of aerosol composition and concentration on the development and anvil properties of a continental deep convective cloud. Quart. J. Roy. Meteor. Soc., 133, 1439-1452.

Emanuel, K. A., J. D. Neelin, and C. S. Bretherton, 1994: On large-scale circulations in convecting atmospheres. Quart. J. Roy. Meteor. Soc., 120, 1111-1143.

Findeisen, W., 1938: Die kolloidmeteorologischen Vorgänge bei der Niederschlagsbildung (Colloidal meteorological processes in the formation of precipitation). Met. Z., 55, 121-133.

Fletcher, N. H., 1962: The physics of Rain Clouds. The Cambridge University Press, 386 pp.

Grabowski, W. W., X. Wu, M. W. Moncrieff, and D. Hall, 1998: Cloud-resolving modeling of cloud systems during Phase III of GATE. Part II: Effects of resolution and the third spatial dimension. J. Atmos. Sci., 55, 3264-3282.

Grabowski, W. W., 2001: Coupling cloud processes with the large-scale dynamics using the cloud-resolving convection parameterization (CRCP). J. Atmos. Sci., 58, 978997. 
Hallett, J., and S. C. Mossop, 1974: Production of secondary ice particles during the riming process. Nature, 249, 26-28.

Houze Jr., R. A., 1977: Structure and dynamics of a tropical squall-line system. Mon. Wea. Rev., 105, 1540-1567.

Iguchi T., and R. Meneghini, 1994: Intercomparison of single-frequency methods for retrieving a vertical rain profile from airborne or spaceborne radar data. J. Atmos. Oceanic Tech., 11, 1507-1517.

Iguchi T., T. Kozu, R. Meneghini, J. Awaka, and K. Okamoto, 2000: Rain-profiling algorithm for the TRMM precipitation radar. J. Appl. Meteor., 39, 2038-2052.

IPCC, Climate Change 2007: The physical science basis. Contribution of Working Group I to the fourth assessment report of the Intergovernmental Panel on Climate Change, Cambridge Univ. Press, Cambridge, United Kingdom and New York, NY, USA, 2007, 996pp.

Jiang, H., W. R. Cotton, J. O. Pinto, J. A. Curry, and M. J. Weissbluth, 2000: Cloud resolving simulations of mixed-phase Arctic stratus observed during BASE: Sensitivity to concentration of ice crystals and large-scale heat and moisture advection. J. Atmos. Sci., 57, 2105-2117.

Johnson, R. H., P. E. Ciesielski, B. D. McNoldy, P. J. Rogers and R. K. Taft, 2007: Multiscale variability of the flow during the north American monsoon experiment. J. Climate, 20, 1628-1648.

Klemp, J. B. and R. B. Wilhelmson, 1978: The simulation of three-dimensional convective storm dynamics. J. Atmos. Sci., 35, 1070-1096.

Koenig, L. R., 1971: Numerical modeling of ice deposition. J. Atmos. Sci., 28, 226-237. 
Korolev, A. V., and I. P. Mazin, 2003: Supersaturation of water vapor in clouds. $J$. Atmos. Sci., 60, 2957-2974.

Kummerow C. D., Coauthors, 2001: The evolution of the Goddard profiling algorithm (GPROF) for rainfall estimation from passive microwave sensors. J. Appl. Meteor., 40, 1801-1820.

Lang, S., W.-K. Tao, R. Cifelli, W. Olson, J. Halverson, S. Rutledge, and J. Simpson, 2007: Improving simulations of convective systems from TRMM LBA: Easterly and westerly regimes. J. Atmos. Sci., 64, 1141-1164.

Lindzen, R. S., 1990: Some coolness concerning global warming. Bull. Amer. Meteor. Soc., 71, 288-299.

Lohmann, U., and J. Feichter, 2005: Global indirect aerosol effects: a review. Atmos. Chem. Phys., 5, 715-737.

Manabe, S. and R. F. Strickler, 1964: Thermal equilibrium of the atmosphere with a convective adjustment. J. Atmos. Sci., 21, 361-385.

Matejka, T. J., R. A. Houze, Jr., and P. V. Hobbs, 1980: Microphysics and dynamics of clouds associated with mesoscale rainbands in extratropical cyclones. Quart. J. Roy. Meteor. Soc., 106, 29-56.

Matsui, T., X. Zeng, W.-K. Tao, H. Masunaga, W. S. Olson, and S. Lang, 2009: Evaluation of long-term cloud-resolving model simulations using satellite radiance observations and multi-frequency satellite simulators. J. Atmos. Oce. Tech. (in press). 
Möhler, O., P. J. DeMott, G. Vali, and Z. Levin, 2007: Microbiology and atmospheric processes: the role of biological particles in cloud physics. Biogeosciences, $\mathbf{4}$, 1059-1071.

Moncrieff, M. W. and Coauthors, 1997: GEWEX Cloud system study (GCSS) working group 4: Precipitating convective cloud systems. Bull. Am. Meteor. Soc., 78, 831845.

National Research Council (NRC), 2005: Radiative forcing of climate change: expanding the concept and addressing uncertainties. Nat. Acad. Sci., Washington, DC. 224 pp.

Nesbitt, S. W., R. Cifelli and S. A. Rutledge, 2006: Storm morphology and rainfall characteristics of TRMM precipitation features. Mon. Wea. Rev., 134, 2702-2721.

Olson, W. S., Y. Hong, C. D. Kummerow, and J. Turk, 2001: A texture-polarization method for estimating convective-stratiform precipitation area coverage from passive microwave radiometer data. J. Appl. Meteor., 40, 1577-1591.

Olson, W. S., C. D. Kummerow, S. Yang, G. W. Petty, W.-K. Tao, T. L. Bell, S. A. Braun, Y. Wang, S. E. Lang, D. E. Johnson and C. Chiu, 2006: Precipitation and latent heating distributions from satellite passive microwave radiometry. Part I: Improved method and uncertainties. J. Appl. Meteor. and Climatol., 45, 702-720.

Paluch, I. R., 1979: The entrainment mechanism in Colorado cumuli. J. Atmos. Sci., 36, 2467-2478.

Petch, J. C., and M. E. B. Gray, 2001: Sensitivity studies using a cloud-resolving model simulation of the tropical west Pacific. Quart. J. Roy. Meteor. Soc., 127, 22872306. 
Phillips V. T. J., Coauthors, 2005: Anvil glaciation in a deep cumulus updraft over Florida simulated with an Explicit Microphysics Model. I: The impact of various nucleation processes. Quart. J. Roy. Meteor. Soc., 131, 2019-2046.

Phillips, V. T. J., L. J. Donner and S. T. Garner, 2007: Nucleation processes in deep convection simulated by a cloud-system-resolving model with double-moment bulk microphysics. J. Atmos. Sci. 64, 738-761.

Phillips, V. T. J., P. J. DeMott, and C. Andronache, 2008: An empirical parameterization of heterogeneous ice nucleation for multiple chemical species of aerosol. $J$. Atmos. Sci. 65, 2757-2783.

Plaude, N. O., E. A. Stulov, N. A. Monakhova, M. V. Vychuzhanina, E. V. Sosnikova, and N. P. Grishina, 2007: Effects of the city of Moscow on the atmospheric aerosol characteristics in the environs. Russ. Meteor. Hydro., 32, 743-749.

Prenni, A. J., J. Y. Harrington, M. Tjernström, P. J. DeMott, A. Avramov, C. N. Long, S. M. Kreidenweis, P. Q. Olsson, and J. Verlinde, 2007: Can ice-nucleating aerosols affect arctic seasonal climate? Bull. Amer. Meteor. Soc., 88, 541-550.

Pruppacher, H. R., and J. D. Klett, 1997: Microphysics of clouds and precipitation. Kluwer, 954 pp.

Ramanathan, V. and Coauthors: 2007: Warming trends in Asia amplified by brown cloud solar absorption. Nature, 448, doi:10.1038/nature06019.

Randall, D. A. and Coauthors, 2003: Confronting models with data: The GEWEX cloud systems study. Bull. Amer. Meteor. Soc., 84, 455-469.

Richardson, M. S., P. J. DeMott, S. M. Kreidenweis, D. J. Cziczo, E. J. Dunlea, J. L. Jimenez, D. S. Thomson, L. L. Ashbaugh, R. D. Borys, D. L. Westphal, G. S. 
Casuccio, and T. L. Lersch, 2007: Measurements of heterogeneous ice nuclei in the western United States in springtime and their relation to aerosol characteristics. J. Geophys. Res., 112, D02209 doi:10.1029/2006JD007500.

Rutledge, S. A. and P. V. Hobbs, 1984: The mesoscale and microscale structure and organization of clouds and precipitation in mid-latitude clouds. Part XII: A diagnostic modeling study of precipitation development in narrow cold frontal rainbands. J. Atmos. Sci., 41, 2949-2972.

Schlesinger, W. H. and Coauthors, 1990: Biological feedbacks in global desertification. Science, 247, $1043-1048$.

Simpson, J., R. F. Adler and G. R. North, 1988: A proposed Tropical Rainfall Measuring Mission (TRMM) satellite. Bull. Amer. Meteor. Soc., 69, 278-295.

Smolarkiewicz, P. K., and W. W. Grabowski, 1990: The multidimensional positive advection transport algorithm: non-oscillatory option. J. Comp. Phys., 86, 355375.

Soong, S.-T. and Y. Ogura, 1980: Response of tradewind cumuli to large-scale processes. J. Atmos. Sci., 37, 2035-2050.

Starr, D. O., and S. K. Cox, 1985: Cirrus clouds. Part I: cirrus cloud model. J. Atmos. Sci., 42, 2663-2681.

Steiner M., R. A. Houze Jr., and S. E. Yuter, 1995: Climatological characterization of three-dimensional storm structure from operational radar and rain gauge data. $J$. Appl. Meteor., 34, 1978-2007.

Tao, W.-K. and J. Simpson, 1993: The Goddard Cumulus Ensemble model. Part I: Model description. Terr. Atmos. Oceanic Sci., 4, 19-54. 
Tao, W.-K., S. Lang, J. Simpson, C.-H. Sui, B. Ferrier, and M.-D. Chou, 1996: Mechanisms of cloud-radiation interaction in the Tropics and midlatitudes. $J$. Atmos. Sci., 53, 2624-2651.

Tao, W.-K., J. Simpson, D. Baker, S. Braun, M.-D. Chou, B. Ferrier, D. Johnson, A. Khain, S. Lang, B. Lynn, C.-L. Shie, D. Starr, C.-H. Sui, Y. Wang and P. Wetzel, 2003: Microphysics, radiation and surface processes in the Goddard Cumulus Ensemble (GCE) model. Meteor. Atmos. Phys., 82, 97-137.

Wegener, A., 1911: Thermodynamik der Atmosphäre. J. A. Barth: Leipzig.

Wild, M., A. Ohmura, and K. Makowski, 2007: Impact of global dimming and brightening on global warming. Geophy. Res. Let., 34, doi:10.1029/2006GL028031.

Yuter, S. E., and R. A. Houze Jr., 1995: Three-dimensional kinematic and microphysical evolution of Florida cumulonimbus. Part II: Frequency distributions of vertical velocity, reflectivity, and differential reflectivity. Mon. Wea. Rev., 123, 19411963.

Zeng, X., W.-K. Tao, M. Zhang, C. Peters-Lidard, S. Lang, J. Simpson, S. Kumar, S. Xie, J. L. Eastman, C.-L. Shie and J. V. Geiger, 2007: Evaluating clouds in long-term cloud-resolving model simulations with observational data. J. Atmos. Sci., 64, 4153-4177.

Zeng, X., 2008a: The influence of radiation on ice crystal spectrum in the upper troposphere. Quart. J. Roy. Meteor. Soc., 134, 609-620. 
Zeng, X., W.-K. Tao, S. Lang, A. Y. Hou, M. Zhang, and J. Simpson, 2008b: On the sensitivity of atmospheric ensembles to cloud microphysics in long-term cloudresolving model simulations. J. Meteo. Soc. Japan, 86A, 45-65.

Zeng, X., W.-K. Tao, M. Zhang, A. Y. Hou, S. Xie, S. Lang, X. Li, D. Starr, X. Li, and J. Simpson, 2009: An indirect effect of ice nuclei on atmospheric radiation. $J$. Atmos. Sci., 66, 41-61.

Zhang, R., G. Li, J. Fan, D. L. Wu and M. J. Molina, 2007: Intensification of Pacific storm track linked to Asian pollution. PNAS, 104, 5295-5299.

Zipser, E. J., 1969: The role of organized unsaturated convective downdrafts in the structure and rapid decay of an equatorial disturbance. J. Appl. Meteor., 8, 799814. 


\section{Caption}

Figure 1 Schematic of a cloud cluster with an anvil. A cirrus anvil extends laterally outward from the precipitating core of the cluster and modulates solar and infrared radiation. Ice crystals and water droplets, denoted with stars and circles respectively, coexist in the middle troposphere and thus provide an environment for the Bergeron and riming processes. Updrafts transport surviving supercooled droplets into the upper troposphere where they then freeze. With increasing IN concentration, the surviving supercooled droplets in the middle troposphere and thus the ice crystals in the upper troposphere increase correspondingly (see Sections 2.b and 2.c for details).

Figure 2 Meridional variations in stratiform precipitation fraction derived from 10 years of TRMM PR and TMI data. Dashed lines are estimated to represent the tendency beyond $37^{\circ}$.

Figure 3 Meridional variations in stratiform precipitation fraction derived from 10 years of TRMM PR (top) and TMI data (bottom) for four seasons: northern-hemispheric winter (thick solid), spring (thick dashed), summer (thin solid) and fall (thin dashed line).

Figure 4 Geographic locations of the ten field campaigns from which data are used to drive and evaluate the present CRM simulations.

Figure 5 Mean mixing ratio of cloud ice $q_{i}$ (left) and $q_{c} q_{g}$, the product of the mixing ratios of cloud water and graupel (right), as functions of pressure and vertical velocity $w$ 
in the mixed-phase region of the NAME simulation with IN category IV. The units of $q_{i}$ and $q_{c} q_{g}$ are $\mathrm{g} / \mathrm{kg}$ and $10^{-1}(\mathrm{~g} / \mathrm{kg})^{2}$, respectively.

Figure 6 As in Fig. 5, but for the GATE simulation with IN category V (top) and the ARM-SGP-00 simulation with IN category II (bottom).

Figure 7 Upper-tropospheric ice content and TOA radiative flux versus IN concentration over various geographic regions. Modeled cloud ice content above $7.4 \mathrm{~km}$ (top) and net downward radiative flux at the TOA (bottom) vary with IN concentration, which are obtained from the CRM simulations over the ten field campaigns. One line corresponds to one field campaign. Red and blue lines display the mid-latitudinal results in spring and summer, respectively; green and black lines display sub-tropical and tropical results, respectively. The horizontal axis represents the IN concentration calculated with the Fletcher formula at a temperature of $-10^{\circ} \mathrm{C}$. Red labels correspond to red lines.

Figure 8 Model biases versus assigned IN concentration in mid-latitudes. Biases in modeled upward infrared flux at the TOA (thin lines in the lower panel), precipitable water (thick lines) and surface precipitation rate (thin lines in the upper panel) vary with the assigned IN concentration at $-10^{\circ} \mathrm{C}$. A zero bias corresponds to an in-situ active IN concentration. Red and blue lines represent the results in spring and summer, respectively. 
Figure 9 Increase in the upward solar flux (black) and decrease in the upward infrared flux (red) at the TOA from doubling the IN concentration versus latitude. All of the results are obtained from the CRM simulations for the ten field campaigns.

Figure 10 Increase in the net radiative flux at the TOA from doubling the current IN concentration versus latitude. All of the results are obtained from the CRM simulations over the ten field campaigns. Thick and thin solid lines are introduced to fit the results to spring and summer, respectively, based on Figs. 2 and 3. The dashed line represents the increase in the net radiative flux when the atmospheric $\mathrm{CO}_{2}$ concentration is increased from a pre-industrial value of about $280 \mathrm{ppm}$ to $379 \mathrm{ppm}$ in 2005 . The vertical axis also scales to the increase in surface temperature from doubling the IN concentration when $\lambda=0.25 \mathrm{~K}\left(\mathrm{~W} \mathrm{~m}^{-2}\right)^{-1}$.

Figure 11 A flowchart showing the effect of global desertification and industrialization on warming via IN and supercooled droplets, where IN affect the Wegener and Bergeron processes directly and graupel riming indirectly via the amount of available supercooled droplets. All the processes in the blue area are explicitly modeled in the present CRM simulations. 
Table 1 Field campaigns and corresponding CRM simulations

\begin{tabular}{|c|c|c|c|c|}
\hline Field Campaign & Latitude & Starting Date & Modeling Days & IN Category \\
\hline ARM-SGP-97 & \multirow{3}{*}{$37^{\circ} \mathrm{N}$} & 18 Jun 1997 & 29 & I, II, IV, V \\
\hline ARM-SGP-00 & & 1 Mar 2000 & 20 & I, II, IV, V \\
\hline ARM-SGP-02 & & 25 May 2002 & 20 & I, II, III, IV, V \\
\hline NAME & $26^{\circ} \mathrm{N}$ & 7 July 2004 & 40 & II, III, IV, V \\
\hline SCSMEX/NESA & $21^{\circ} \mathrm{N}$ & 6 May 1998 & 44 & $\mathrm{IV}, \mathrm{V}, \mathrm{VI}$ \\
\hline TWP-ICE & $12^{\circ} \mathrm{S}$ & 19 Jan 2006 & 24 & IV, V \\
\hline GATE & $9^{\circ} \mathrm{N}$ & 1 Sep 1974 & 18 & $\mathrm{IV}, \mathrm{V}, \mathrm{VI}$ \\
\hline KWAJEX & $9^{\circ} \mathrm{N}$ & 24 Jul 1999 & 52 & IV, V \\
\hline SCSMEX/SESA & $5^{\circ} \mathrm{N}$ & 1 May 1998 & 60 & IV, V \\
\hline TOGA-COARE & $2^{\circ} \mathrm{S}$ & 1 Nov 1992 & 61 & $\mathrm{IV}, \mathrm{V}$ \\
\hline
\end{tabular}


Table 2 IN concentration categories used in numerical experiments

\begin{tabular}{|c|c|c|}
\hline IN Category & $\mu n_{0}\left(\mathrm{~cm}^{-3}\right)$ & $\beta$ \\
\hline I & $6.0 \times 10^{-10}$ & 0.3 \\
\hline II & $1.2 \times 10^{-9}$ & 0.4 \\
\hline III & $4.8 \times 10^{-9}$ & 0.45 \\
\hline IV & $1.2 \times 10^{-8}$ & 0.5 \\
\hline V & $1.2 \times 10^{-6}$ & 0.6 \\
\hline VI & $1.2 \times 10^{-5}$ & 0.7 \\
\hline
\end{tabular}


Table 3 Modeled meridional variation in stratiform precipitation percentage

\begin{tabular}{|l|c|c|c|}
\hline Experiment & GATE & NAME & ARM-SGP-00 \\
\hline Latitude & $9^{\circ} \mathrm{N}$ & $26^{\circ} \mathrm{N}$ & $37^{\circ} \mathrm{N}$ \\
\hline Stratiform Precipitation & 35.0 & 44.7 & 53.5 \\
Percentage (\%) & & & \\
\hline
\end{tabular}




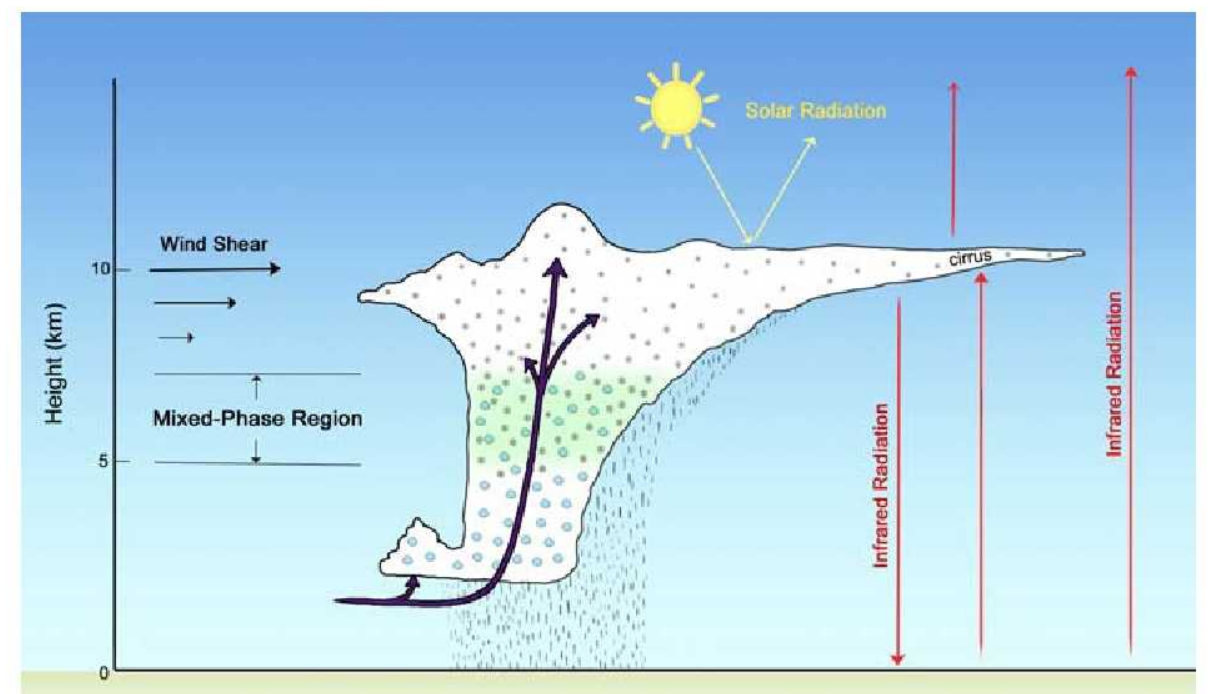

Figure 1 Schematic of a cloud cluster with an anvil. A cirrus anvil extends laterally outward from the precipitating core of the cluster and modulates solar and infrared radiation. Ice crystals and water droplets, denoted with stars and circles respectively, coexist in the middle troposphere and thus provide an environment for the Bergeron and riming processes. Updrafts transport surviving supercooled droplets into the upper troposphere where they then freeze. With increasing IN concentration, the surviving supercooled droplets in the middle troposphere and thus the ice crystals in the upper troposphere increase correspondingly (see Sections 2.b and 2.c for details). 


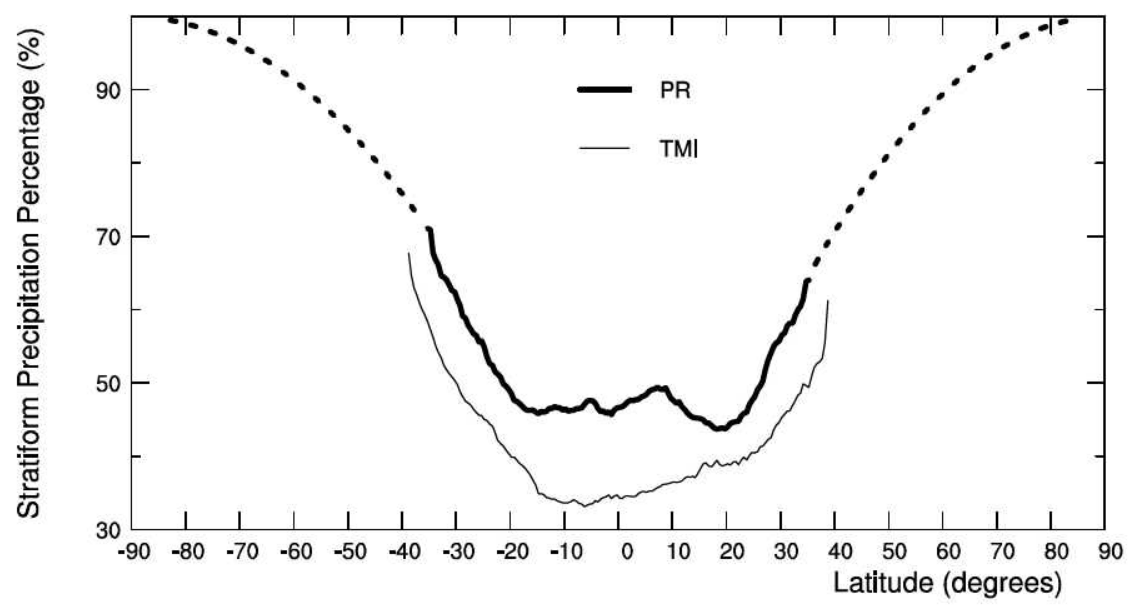

Figure 2 Meridional variations in stratiform precipitation fraction derived from 10 years of TRMM PR and TMI data. Dashed lines are estimated to represent the tendency beyond $37^{\circ}$. 

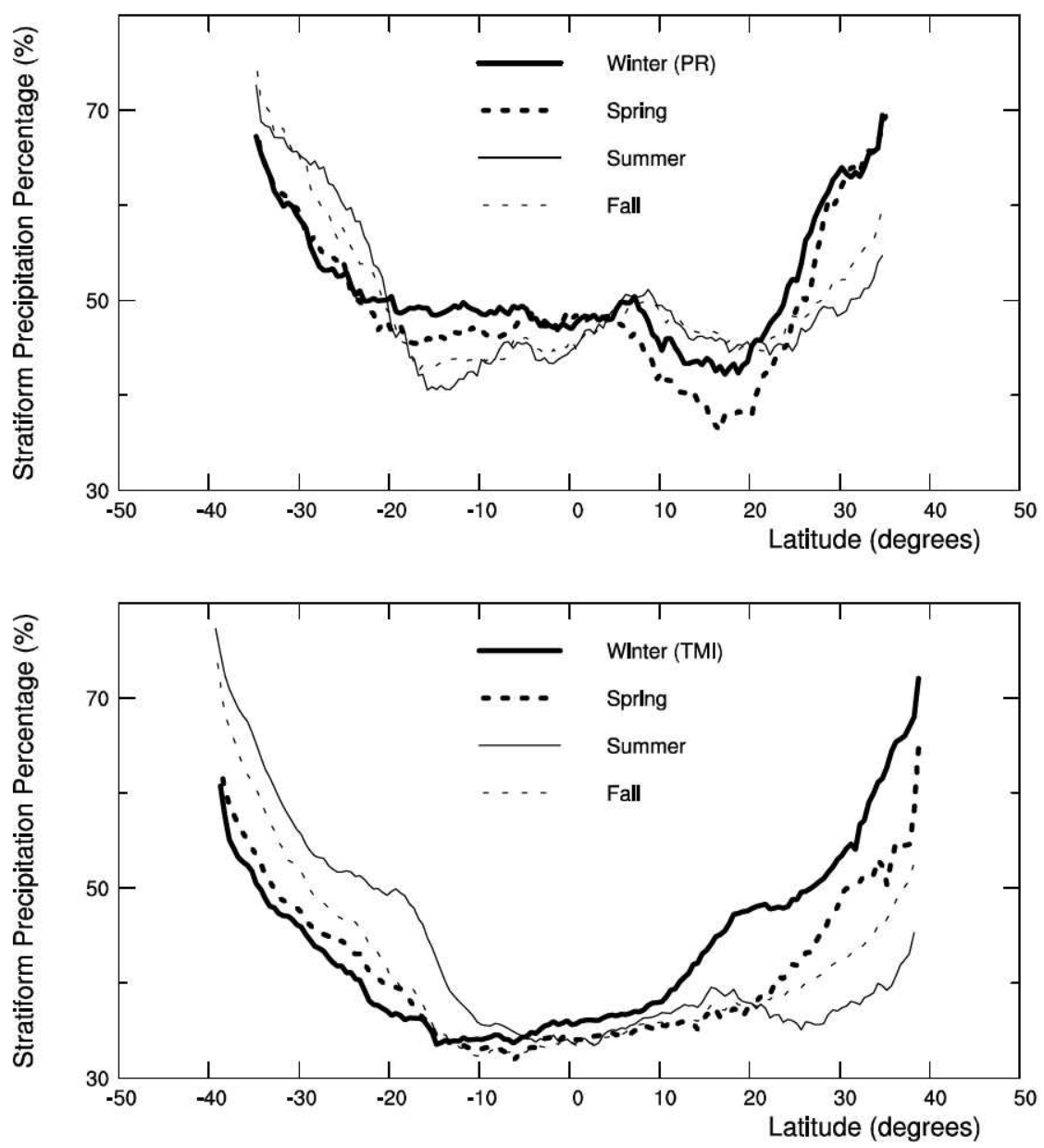

Figure 3 Meridional variations in stratiform precipitation fraction derived from 10 years of TRMM PR (top) and TMI data (bottom) for four seasons: northern-hemispheric winter (thick solid), spring (thick dashed), summer (thin solid) and fall (thin dashed line). 


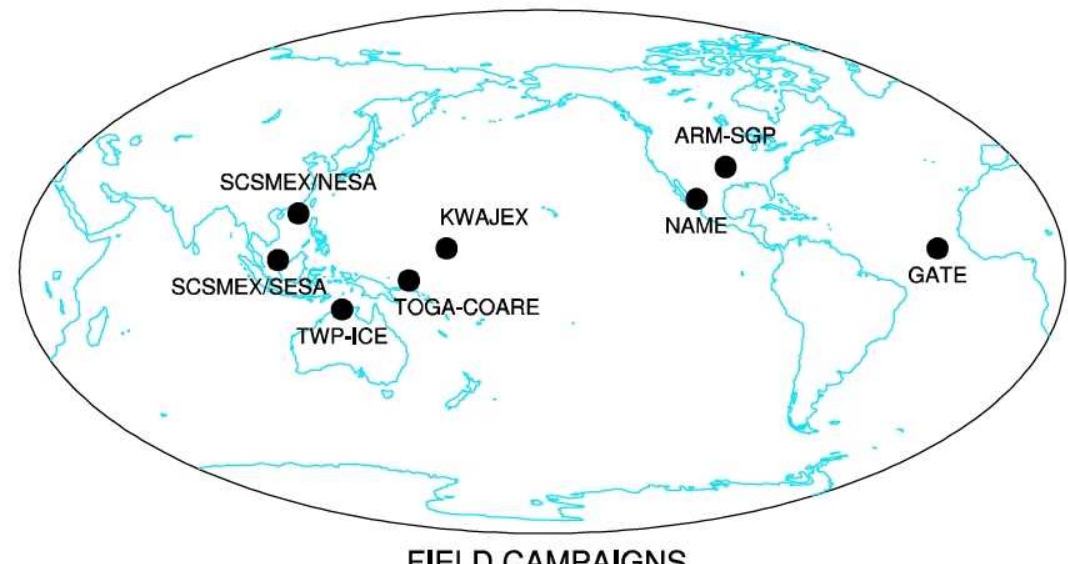

FIELD CAMPAIGNS

Figure 4 Geographic locations of the ten field campaigns from which data are used to drive and evaluate the present CRM simulations. 


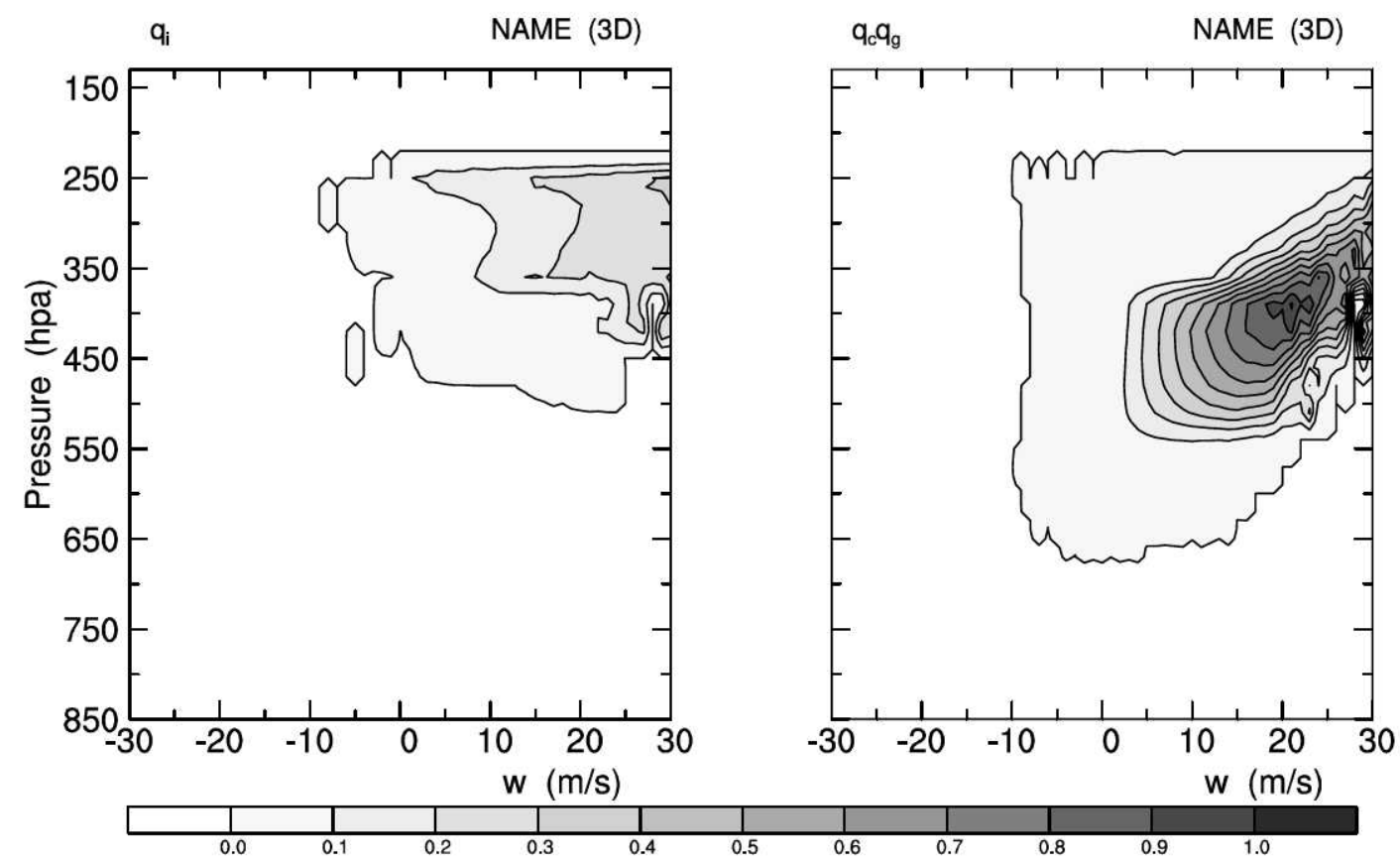

Figure 5 Mean mixing ratio of cloud ice $q_{i}$ (left) and $q_{c} q_{g}$, the product of the mixing ratios of cloud water and graupel (right), as functions of pressure and vertical velocity $w$ in the mixed-phase region of the NAME simulation with IN category IV. The units of $q_{i}$ and $q_{c} q_{g}$ are $\mathrm{g} / \mathrm{kg}$ and $10^{-1}(\mathrm{~g} / \mathrm{kg})^{2}$, respectively. 

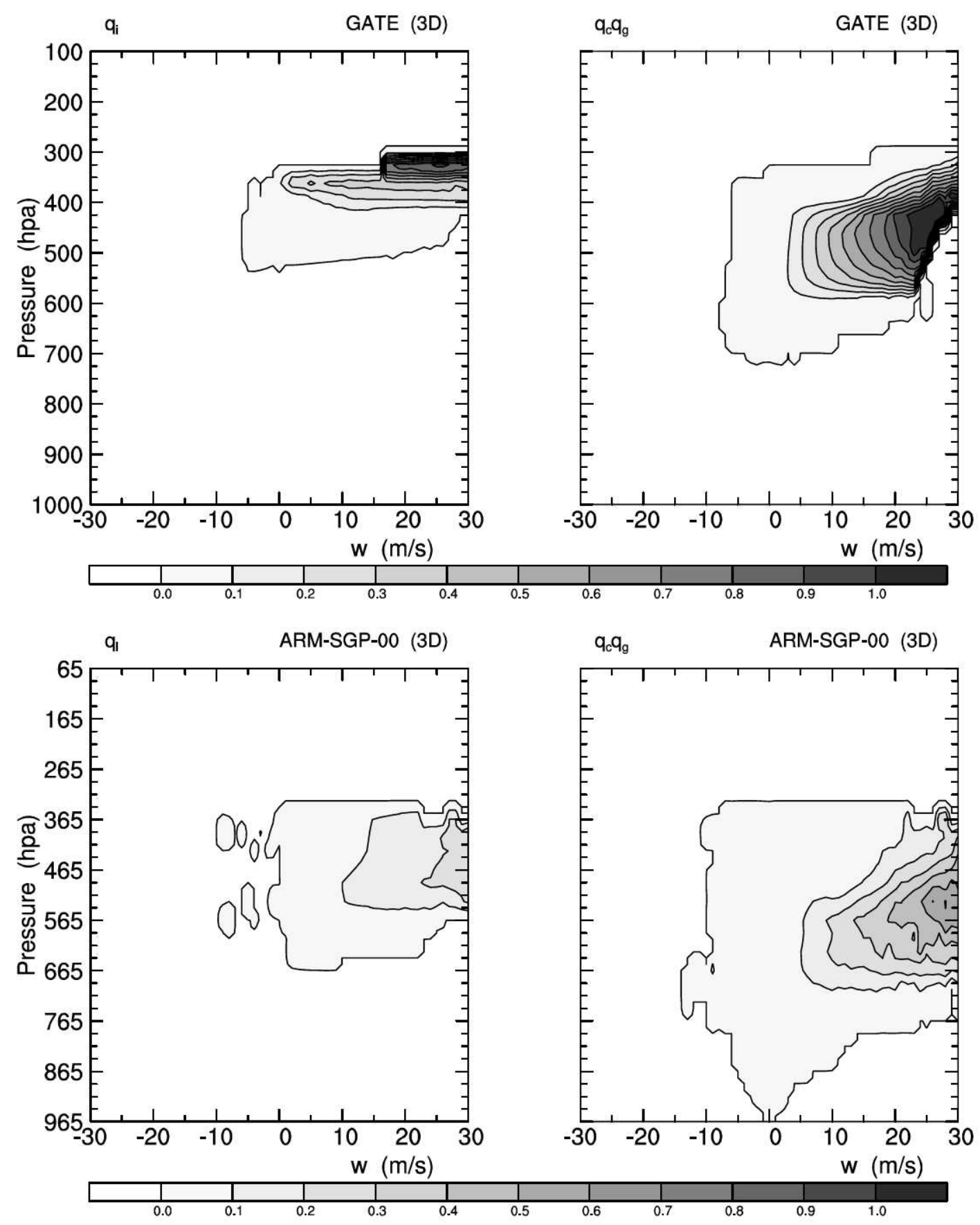

Figure 6 As in Fig. 5, but for the GATE simulation with IN category V (top) and the ARM-SGP-00 simulation with IN category II (bottom). 

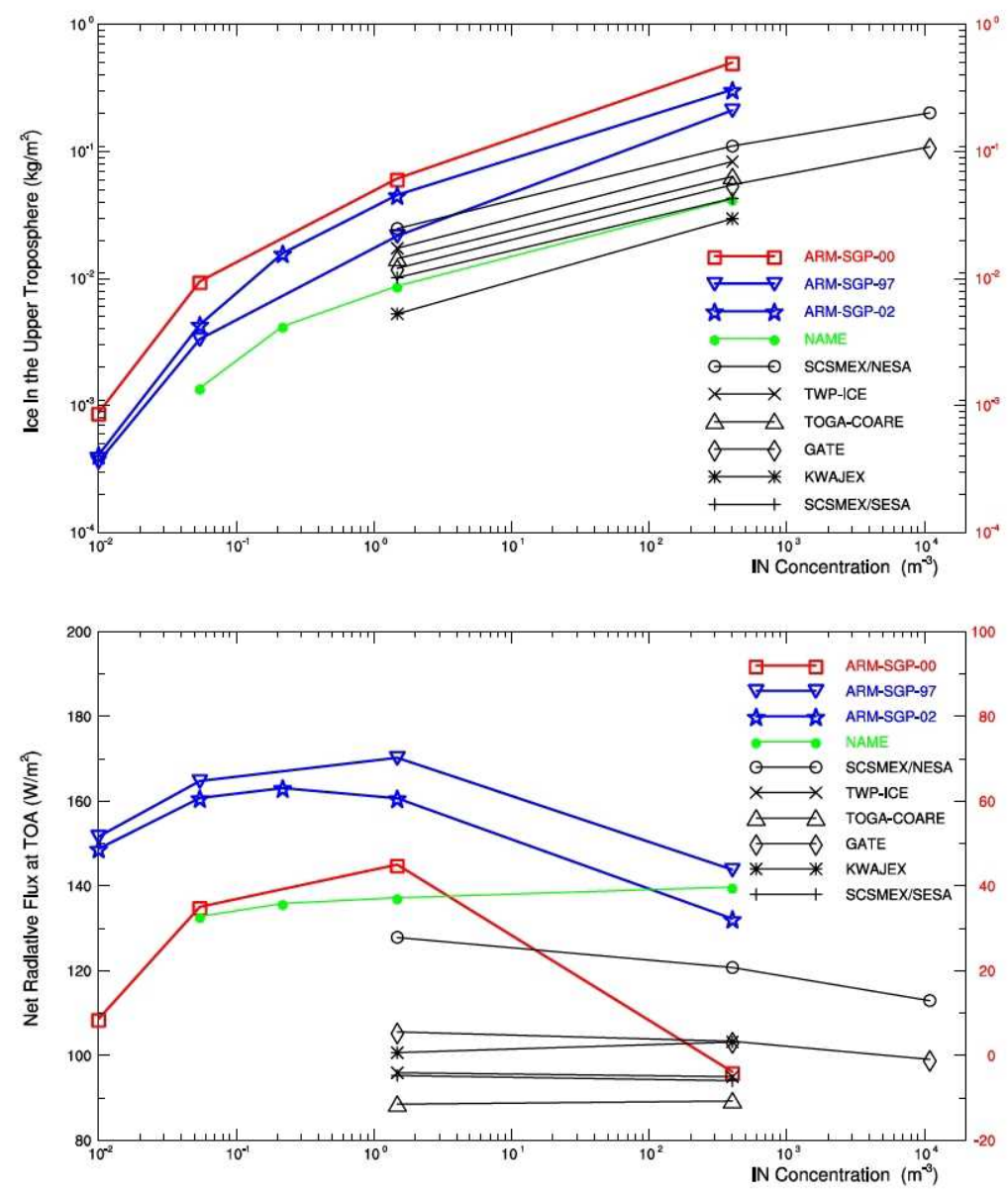

Figure 7 Upper-tropospheric ice content and TOA radiative flux versus IN concentration over various geographic regions. Modeled cloud ice content above $7.4 \mathrm{~km}$ (top) and net downward radiative flux at the TOA (bottom) vary with IN concentration, which are obtained from the CRM simulations over the ten field campaigns. One line corresponds to one field campaign. Red and blue lines display the mid-latitudinal results in spring and summer, respectively; green and black lines display sub-tropical and tropical results, respectively. The horizontal axis represents the IN concentration calculated with the Fletcher formula at a temperature of $-10^{\circ} \mathrm{C}$. Red labels correspond to red lines. 

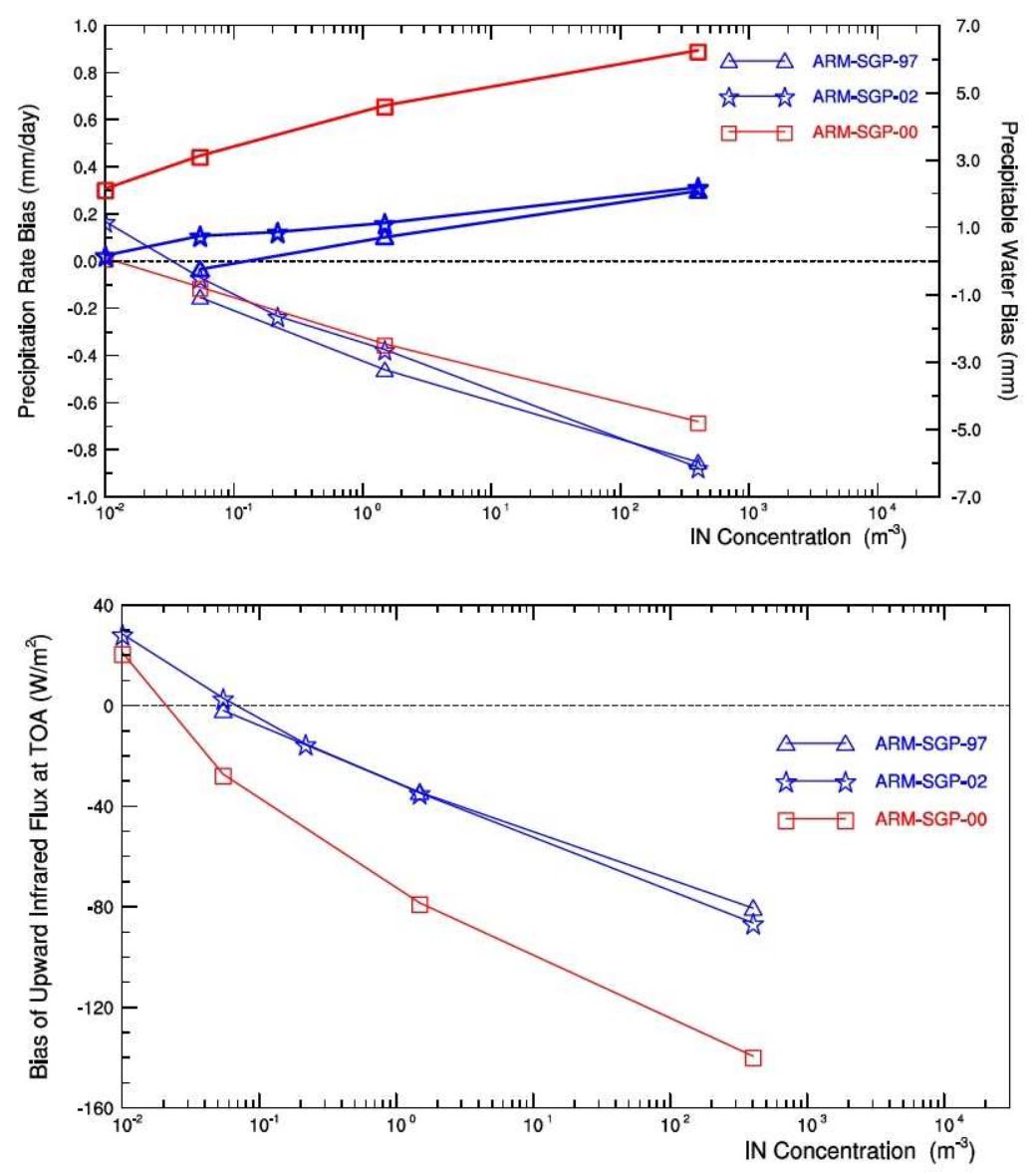

Figure 8 Model biases versus assigned IN concentration in mid-latitudes. Biases in modeled upward infrared flux at the TOA (thin lines in the lower panel), precipitable water (thick lines) and surface precipitation rate (thin lines in the upper panel) vary with the assigned IN concentration at $-10^{\circ} \mathrm{C}$. A zero bias corresponds to an in-situ active IN concentration. Red and blue lines represent the results in spring and summer, respectively. 


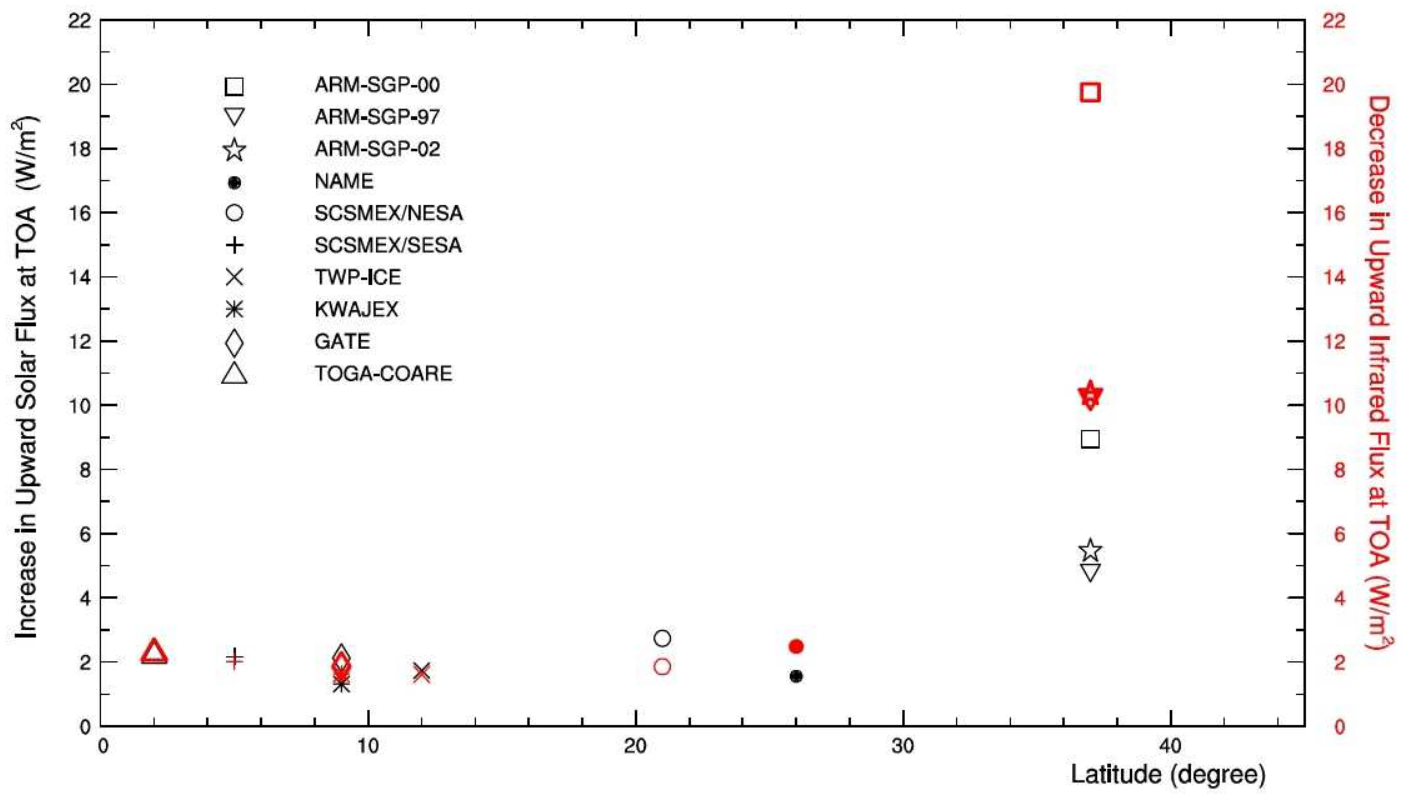

Figure 9 Increase in the upward solar flux (black) and decrease in the upward infrared flux (red) at the TOA from doubling the IN concentration versus latitude. All of the results are obtained from the CRM simulations for the ten field campaigns. 


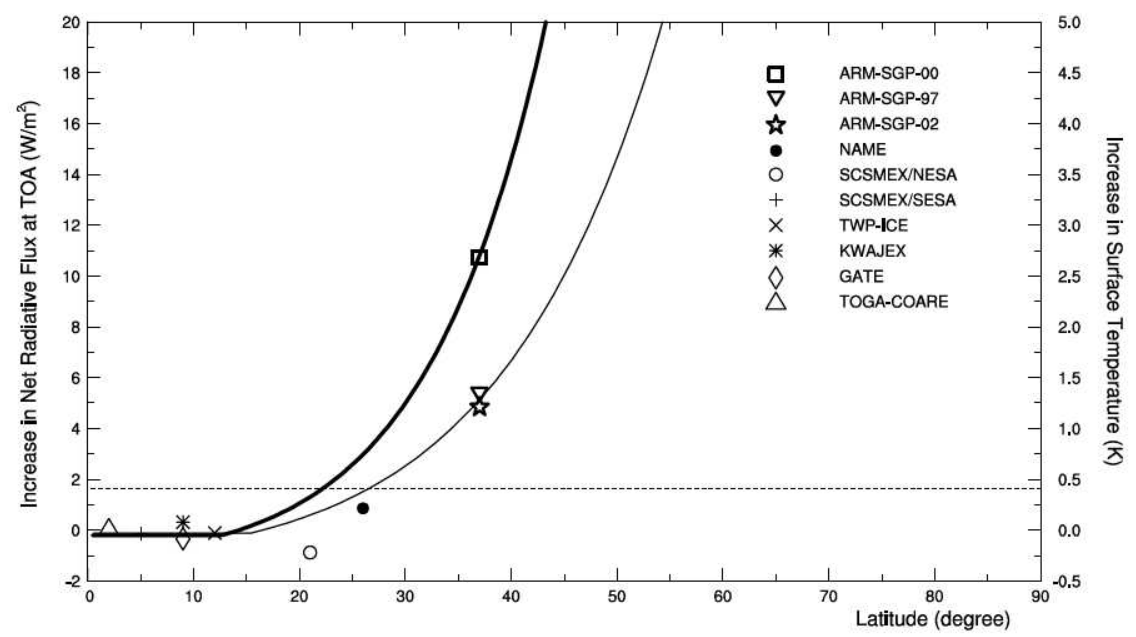

Figure 10 Increase in the net radiative flux at the TOA from doubling the current IN concentration versus latitude. All of the results are obtained from the CRM simulations over the ten field campaigns. Thick and thin solid lines are introduced to fit the results to spring and summer, respectively, based on Figs. 2 and 3. The dashed line represents the increase in the net radiative flux when the atmospheric $\mathrm{CO}_{2}$ concentration is increased from a pre-industrial value of about $280 \mathrm{ppm}$ to $379 \mathrm{ppm}$ in 2005 . The vertical axis also scales to the increase in surface temperature from doubling the IN concentration when $\left.\lambda=0.25 \mathrm{~K}_{(\mathrm{W} \mathrm{m}}{ }^{-2}\right)^{-1}$. 


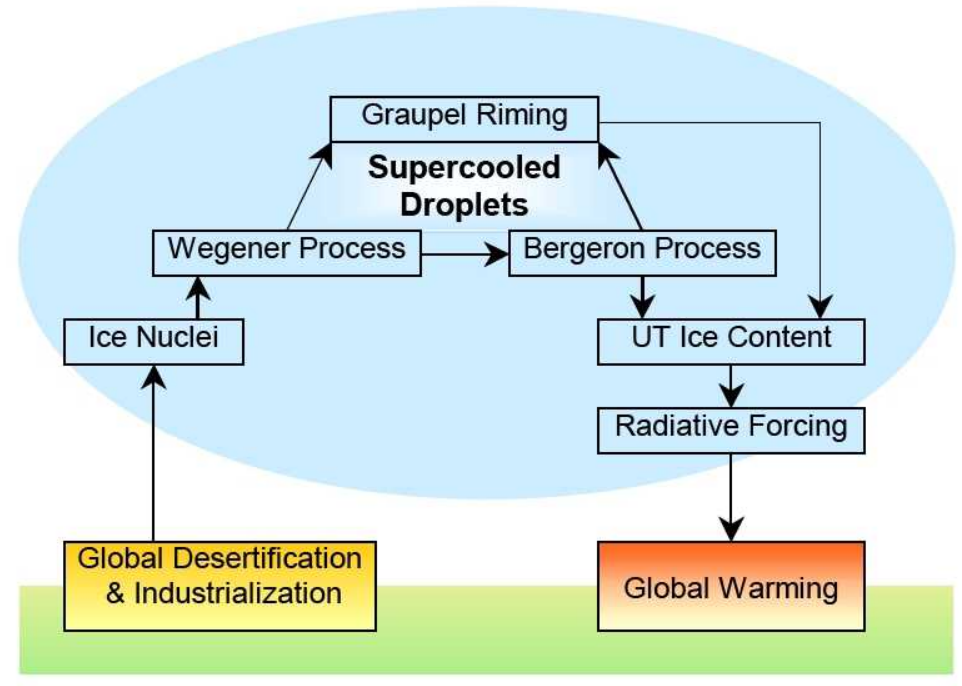

Figure 11 A flowchart showing the effect of global desertification and industrialization on warming via IN and supercooled droplets, where IN affect the Wegener and Bergeron processes directly and graupel riming indirectly via the amount of available supercooled droplets. All the processes in the blue area are explicitly modeled in the present CRM simulations. 